\title{
Article \\ Axial Compression Behavior of Symmetrical Full-Scale Concrete Filled Double Skin Steel Tube Stub Columns
}

\author{
Wen Bai ${ }^{1}$, Yunhao $\mathrm{Li}^{2}$, Jing $\mathrm{Ji}^{1,2}$, Yuchen Liu ${ }^{3, *}$, Lei Zhang ${ }^{3}$, Ruili Wang ${ }^{4, *}$, Liangqin Jiang ${ }^{1,2}$ and Lingjie He ${ }^{2}$ \\ 1 Key Laboratory of Earthquake Engineering and Engineering Vibration, Institute of Engineering Mechanics, \\ China Earthquake Administration, Harbin 150086, China; baiwen@iem.ac.cn (W.B.); jijing@nepu.edu.cn (J.J.); \\ jiangliangqin@nepu.edu.cn (L.J.) \\ 2 Heilongjiang Key Lab of Disaster Prevention, Mitigation and Protection Engineering, Northeast Petroleum \\ University, Daqing 163318, China; liyunhao19970806@163.com (Y.L.); hljessica1998@163.com (L.H.) \\ 3 Handan Key Laboratory of Building Physical Environment, Regional Building Protection Technology, School \\ of Architecture and Art, Hebei University of Engineering, Handan 056009, China; hbzhanglei2021@163.com \\ 4 School of Management Engineering and Business, Hebei University of Engineering, Handan 056009, China \\ * Correspondence: liuyuchen@hebeu.edu.cn (Y.L.); yuanguanghua@hebeu.edu.cn (R.W.)
}

Citation: Bai, W.; Li, Y.; Ji, J.; Liu, Y.; Zhang, L.; Wang, R.; Jiang, L.; He, L. Axial Compression Behavior of Symmetrical Full-Scale Concrete Filled Double Skin Steel Tube Stub Columns. Symmetry 2022, 14, 223. https://doi.org/10.3390/ sym 14020223

Academic Editor: Igor V. Andrianov

Received: 21 October 2021

Accepted: 8 December 2021

Published: 24 January 2022

Publisher's Note: MDPI stays neutral with regard to jurisdictional claims in published maps and institutional affiliations.

Copyright: (C) 2022 by the authors. Licensee MDPI, Basel, Switzerland. This article is an open access article distributed under the terms and conditions of the Creative Commons Attribution (CC BY) license (https:// creativecommons.org/licenses/by/ $4.0 /)$.

\begin{abstract}
To investigate the bearing behavior of symmetrical full-scale different strength concrete filled double skin steel tube (CFDST) stub columns, 19 full-scale specimens were designed, considering the slenderness ratio $(\lambda)$; the compression strength of core concrete and sandwich concrete $\left(f_{\text {cki }}, f_{\text {cko }}\right)$, the thickness of the inner and outer steel tubes $\left(t_{\mathrm{i}}, t_{\mathrm{o}}\right)$; the diameter of inner and outer steel tubes $\left(D_{\mathrm{i}}, D_{\mathrm{o}}\right)$; and the tensile strength of the inner and outer steel tubes $\left(f_{\mathrm{yki}}, f_{\mathrm{yko}}\right)$ as the main parameters. Nonlinear constitutive models for concrete considering constraint effect were adopted, and a finite element (FE) model was established using ABAQUS software. By comparing the results between simulations and experiments, the rationality of the modeling method was verified. Based on the FE model, the parameter analysis for CFDST columns were conducted, and the force mechanism, stress distribution, and deformation process were analyzed. The results showed that the axial compression bearing capacity $\left(N_{\mathrm{s}}^{\mathrm{u}}\right)$ increased significantly with an increase in $f_{\mathrm{cki}}, t_{\mathrm{o}}, D_{\mathrm{o}}$, and $f_{\text {cko }}$, while $N_{\mathrm{s}}^{\mathrm{u}}$ decreased gradually with an increase in $\lambda$. Finally, according to the calculated results of the specimens, the calculation formula for $N_{\mathrm{s}}^{\mathrm{u}}$ of full-scale composite columns was statistically regressed using 1stOpt software and showed a good agreement with the FE.
\end{abstract}

Keywords: different strength concrete; double skin steel tube; composite columns; constraint effect; finite element simulation; full-scale; axial compression bearing capacity

\section{Introduction}

With the rapid revitalization of old industrial bases in northeastern China, the reconstruction of adding stories around the existing buildings has become a hot topic in the field of civil engineering [1,2]. The main existing buildings are low masonry buildings which were constructed over decades, and they cannot be destroyed or rebuilt to meet their special requirements [3]. The bearing capacity of these buildings is lower, and it is impossible to add stories directly around the existing structures. Therefore, it has become a key problem to realize the reconstruction of adding stories around the existing buildings without interrupting their function [4]. A novel assembled composite frame, consisting of different strength concrete filled double skin steel tube (CFDST) columns and H-shaped honeycombed composite beams with rectangular concrete filled steel tube (RCFST) flanges, is proposed in this paper [5-9]. Both the columns and beams are connected together through integral joints. The sketch of the composite frame is shown in Figure 1. In order to increase the span of frame, external prestressing tendons can be arranged under the low flange of the composite beams. Firstly, the beams and columns of the frame can be prefabricated in the factory and then connected reliably through integral joints in the construction site, 
and, additionally, concrete is poured into the integral joints. The main structure can be continuously constructed from the lower floor to the top floor, which can greatly reduce the construction period.

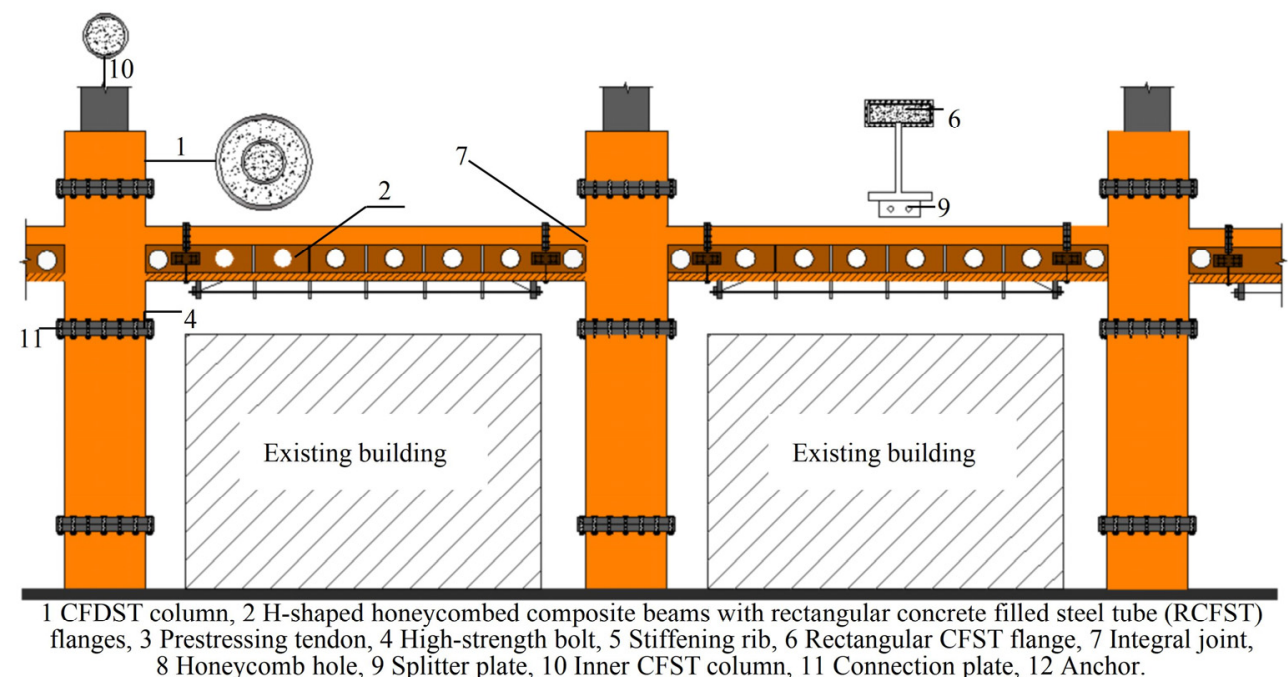

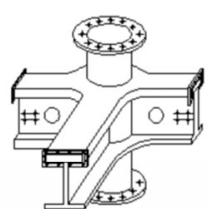

(b) (a)

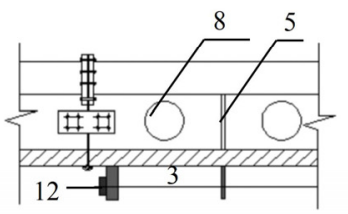

(c)

Figure 1. The sketch: (a) the novel assembled composite frame; (b) integral joint; and (c) H-shaped honeycombed composite beams with RCFST.

CFDST columns consist of inner and outer steel tubes, the core concrete that is poured into the inner steel tube, and the sandwich concrete that is poured between the inner and outer steel tubes. Same strength or different strength concrete can be adopted as the core and sandwich concrete. The outer steel tube has the role of constraining the entire column, and the inner steel tube does not only constrain the core concrete directly, but also provides support to the sandwich concrete. The interaction between the inner steel tube and outer steel tube can result in the stress of the core and sandwich concrete from three directions. Due to the existence of concrete, the local buckling of steel tubes can be delayed or avoided, so their circumferential tensile behavior can be displayed adequately. The axial compression bearing capacity of CFDST columns will greatly be improved, and the ductility and seismic performance will be significantly better than those of ordinary concrete filled single steel tube (CFST) columns [10]. Studies on the bearing behavior of confined concrete members have been widely investigated. In the 1980s, the stress mechanism of reinforcement concrete members was investigated by J. B. Mander et al. [11], and the stress-strain models of reinforcement concrete with various cross-section patterns proposed by C. N. Srinivasan et al. [12] experimentally investigated the axial compression behavior of 14 CFST stub columns. The results showed that the ductility and stiffness of these members were improved because of the existence of steel tubes. Compared with the ductility and stiffness of square and rectangle CFST columns, those of circular CFST columns were improved more significantly. A series of studies on the eccentric compression [13], stability [14], and fire resistance [15] behavior of CFST columns were carried out, and the specimens showed excellent strength, stiffness, and stability when subjected to various complicated loading. Compared with ordinary reinforced concrete frame structures, the frame structure composed by CFST members had superior seismic behavior and impact resistance. A series of studies on the axial compression behavior of 
CFST columns and CFDST columns were carried out by Hussein Ghanim Hasan et al., and the results showed that the inner tube played a significant role in the performance of CFDST columns. With the increase in the thickness of the inner tube, the influence of the constraint effect increased; therefore, it was necessary to consider the constraint effect of the inner tube during the process of calculation and analysis [16]. In addition, the destructive form of the CFDST columns depended mainly on the D/t of the outer tube, and when compared with the inner tube with the thick wall, the inner tube of the specimens suffered greater damage in the early bending stage [17]. The axial compression behavior of the hollow CFDST composite columns was experimentally investigated by Z. Tao [18]. By the introduction of the constraint effect coefficient $(\xi)$, the stress-strain model [19], which could be suitable for hollow CFDST composite columns, was established. Based on the theory of confined concrete, the stress mechanism of fiber reinforced polymer (FRP) confined concrete members was investigated by L. Lam [20] and J. G. Teng [21], and the stress-strain model for concrete confined by FRPs was provided. Numerical simulation analysis of hollow CFDST columns using the finite element (FE) software ABAQUS was conducted by M. Pagoulatou [22], and the FE analysis results were in agreement with the experiments. An analytical expression for calculating the axial compression bearing capacity of the members was proposed according to the parameter analysis. J. G. Nie [23] investigated the behavior of hollow CFDST columns by utilizing the equilibrium limit method, and a simple expression to predict the axial compression bearing capacity for hollow CFDST members was developed. X. D. Fang [24] and T. Ekmekyapar [25] experimentally studied the axial compression behavior of 34 CFDST columns, and the results showed that the failure model of the CFDST members was, essentially, similar to that of the CFST members. Moreover, the axial compression bearing capacity, ductility, and stiffness were significantly improved due to the existence of the double skin steel tubes.

Although the axial compression analysis for the CFDST specimens have been investigated widely, the reduced-scale models were mainly considered and researched [24,26]. Therefore, it is insufficient to conduct the research on the mechanism behavior of CFDST members considering the size effect, and the applicability of the calculation formula for the bearing capacity based on the reduced-scale models to the full-scale specimens has not been verified. According to the mechanism behavior of CFST members, the constraint effect coefficients $\left(\xi_{1}, \xi_{0}\right)$ were introduced to describe the constraint effect for core concrete and sandwich concrete, respectively. A total of 19 full-scale specimens were designed, taking the slenderness ratio $(\lambda)$; the compression strength of the core concrete and sandwich concrete $\left(f_{\text {cki }}, f_{\text {cko }}\right)$; the thickness of the inner and outer steel tubes $\left(t_{\mathrm{i}}, t_{\mathrm{o}}\right)$; the diameter of the inner and outer steel tubes $\left(D_{\mathrm{i}}, D_{\mathrm{o}}\right)$; and the tensile strength of the inner and outer steel tubes $\left(f_{\mathrm{yki}}, f_{\mathrm{yko}}\right)$ as the main parameters. Numerical simulation analysis of the mechanical behavior of full-scale CFDST stub columns subjected to an axial load was carried out using ABAQUS [27], and the rationality of modeling method was verified. The stress distribution and failure mode of the specimens could be obtained. The bearing capacity formula for the full-scale CFDST composite stub columns could be statistically regressed using 1stOpt software, which could be used in engineering practices.

\section{Specimen Design}

To study the axial compression behavior of symmetrical full-scale CFDST stub columns, 19 specimens were designed by considering the slenderness ratio $(\lambda)$, the axial compression strength of the core and sandwich concrete $\left(f_{\text {cki }}, f_{\text {cko }}\right)$, the thickness $\left(t_{\mathrm{i}}, t_{\mathrm{o}}\right)$, and the yield strength $\left(f_{\text {cki }}, f_{\text {cko }}\right)$ and diameter $\left(D_{\mathrm{i}}, D_{\mathrm{o}}\right)$ of the inner and outer steel tubes as the main controlled parameters. These specific parameters are shown in Table 1 and the sketch of the CFDST columns is shown in Figure 2 . The constraint effect coefficients $\left(\xi_{\mathrm{i}}, \xi_{\mathrm{o}}\right)$ [28], which stood for the constraint effect of the core concrete and sandwich concrete, respectively, were listed in Table 1. According to the failure mode of the CFST columns [29], the sandwich concrete was constrained by the outer steel tube, and the only interaction between the inner steel tube and sandwich concrete was the interfacial bonding. During the loading process, 
it was almost impossible to achieve a synchronous deformation between the inner steel tube and sandwich concrete [30]; therefore, the interfacial bonding effect would disappear when the circumferential expansion was very small. To conclude, the interfacial bonding effect between the inner steel tube and sandwich concrete may be ignored during the calculation process of $\xi_{\mathrm{o}}$, as shown in Equation (1). The strength of the inner steel tube and core concrete is simplified with $f_{\text {cko }}$ :

$$
\xi_{\mathrm{o}}=A_{\mathrm{so}} f_{\mathrm{yko}} / A_{\mathrm{c}} f_{\mathrm{cko}}
$$

where $A_{\mathrm{c}}$ and $A_{\mathrm{so}}$ are the cross-sectional areas surrounded by the outer steel tube and the area of the outer steel tube, respectively.

Table 1. The specific parameters of the 19 CFDST specimens.

\begin{tabular}{|c|c|c|c|c|c|c|c|c|c|}
\hline Specimens & 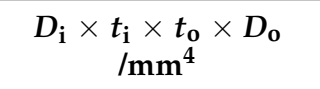 & $\begin{array}{c}h \\
/ \mathrm{mm}\end{array}$ & $\underset{\text { /MPa }}{f_{\text {cki }}}$ & $\begin{array}{c}f_{\mathrm{yki}} \\
/ \mathrm{MPa}\end{array}$ & $\underset{\text { cko }}{f_{\text {cka }}}$ & $\begin{array}{c}f_{\text {yko }} \\
/ \mathrm{MPa}\end{array}$ & $\lambda^{1}$ & $\xi_{\mathrm{i}}$ & $\xi_{0}$ \\
\hline CF1 & $500 \times 10 \times 10 \times 800$ & 1500 & 30 & 345 & 40 & 345 & 7.32 & 1.61 & 0.44 \\
\hline $\mathrm{CF} 2$ & $500 \times 10 \times 10 \times 800$ & 1500 & 40 & 345 & 40 & 345 & 7.32 & 1.39 & 0.44 \\
\hline CF3 & $500 \times 10 \times 10 \times 800$ & 1500 & 50 & 345 & 40 & 345 & 7.32 & 1.26 & 0.44 \\
\hline CF4 & $500 \times 8 \times 10 \times 800$ & 1500 & 40 & 345 & 40 & 345 & 7.32 & 1.25 & 0.44 \\
\hline CF5 & $500 \times 12 \times 10 \times 800$ & 1500 & 40 & 345 & 40 & 345 & 7.32 & 1.53 & 0.44 \\
\hline CF6 & $480 \times 10 \times 10 \times 800$ & 1500 & 40 & 345 & 40 & 345 & 7.32 & 1.38 & 0.44 \\
\hline CF7 & $520 \times 10 \times 10 \times 800$ & 1500 & 40 & 345 & 40 & 345 & 7.32 & 1.41 & 0.44 \\
\hline CF8 & $500 \times 10 \times 10 \times 800$ & 1500 & 40 & 235 & 40 & 345 & 7.32 & 1.18 & 0.44 \\
\hline CF9 & $500 \times 10 \times 10 \times 800$ & 1500 & 40 & 490 & 40 & 345 & 7.32 & 1.67 & 0.44 \\
\hline CF10 & $500 \times 10 \times 10 \times 800$ & 1500 & 40 & 345 & 30 & 345 & 7.32 & 1.63 & 0.58 \\
\hline CF11 & $500 \times 10 \times 10 \times 800$ & 1500 & 40 & 345 & 50 & 345 & 7.32 & 1.25 & 0.35 \\
\hline CF12 & $500 \times 10 \times 8 \times 800$ & 1500 & 40 & 345 & 40 & 345 & 7.35 & 1.26 & 0.35 \\
\hline CF13 & $500 \times 10 \times 12 \times 800$ & 1500 & 40 & 345 & 40 & 345 & 7.28 & 1.52 & 0.53 \\
\hline CF14 & $500 \times 10 \times 10 \times 900$ & 1500 & 40 & 345 & 40 & 345 & 6.52 & 1.23 & 0.39 \\
\hline CF15 & $500 \times 10 \times 10 \times 1000$ & 1500 & 40 & 345 & 40 & 345 & 5.88 & 1.14 & 0.35 \\
\hline CF16 & $500 \times 10 \times 10 \times 800$ & 1500 & 40 & 345 & 40 & 235 & 7.32 & 1.16 & 0.30 \\
\hline CF17 & $500 \times 10 \times 10 \times 800$ & 1500 & 40 & 345 & 40 & 490 & 7.32 & 1.69 & 0.62 \\
\hline CF18 & $500 \times 10 \times 10 \times 800$ & 1200 & 40 & 345 & 40 & 345 & 5.85 & 1.39 & 0.44 \\
\hline CF19 & $500 \times 10 \times 10 \times 800$ & 1600 & 40 & 345 & 40 & 345 & 7.80 & 1.39 & 0.44 \\
\hline
\end{tabular}

${ }^{1} h$ was the length of the specimens. $\lambda=4 h / D_{\mathrm{o}}$.

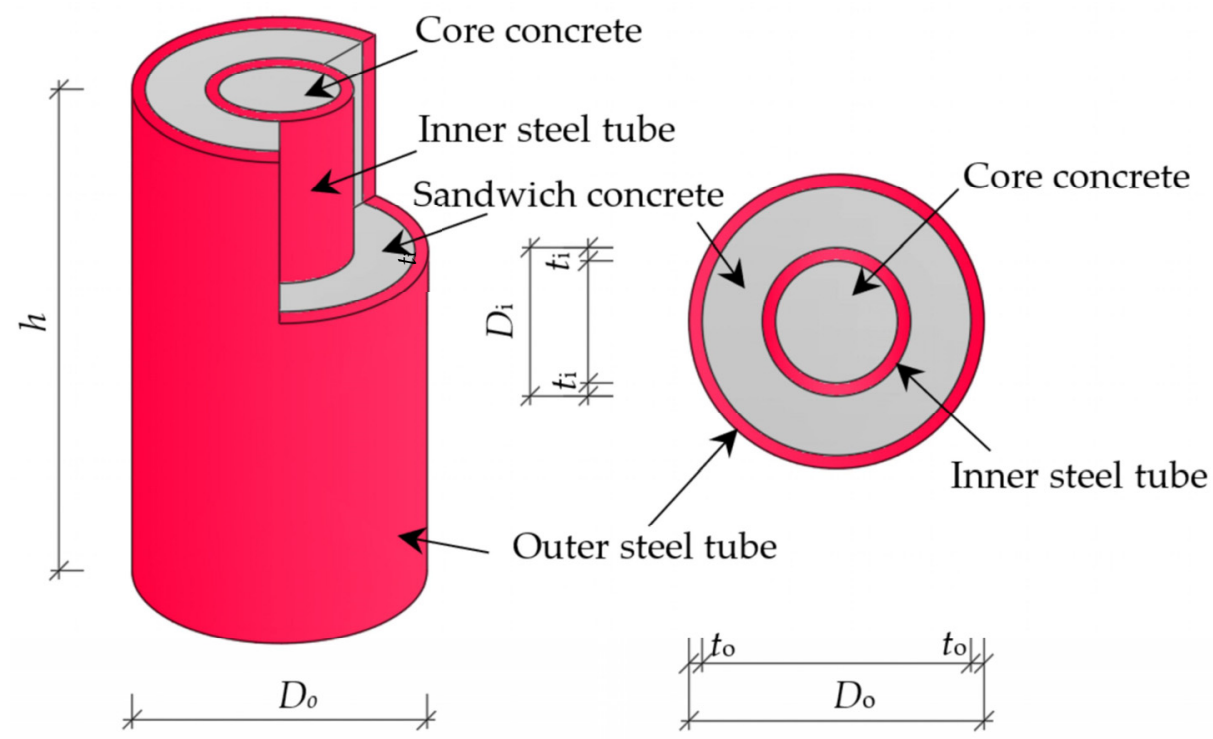

Figure 2. Sketch of the CFDST column. 
The core concrete was directly constrained by the inner steel tube and constrained indirectly by the sandwich concrete and the outer steel tube; therefore, the constraint effect of the core concrete was more complex than the sandwich concrete. Here, $\xi_{i}$ was adopted to describe the equivalent constraint effect of the core concrete, and the calculation expression is shown in Equation (2) as the following:

$$
\xi_{\mathrm{i}}=\frac{A_{\mathrm{c}}}{A}\left(\frac{A_{\mathrm{si}} f_{\mathrm{yki}}}{A_{\mathrm{ci}} f_{\mathrm{cki}}}+\frac{A_{\mathrm{so}} f_{\mathrm{yko}}}{A_{\mathrm{co}} f_{\mathrm{cko}}}\right)
$$

where $A$ is the total cross-sectional area of the CFDST specimens. $A_{\mathrm{si}}, A_{\mathrm{ci}}$, and $A_{\mathrm{co}}$ are the cross-sectional areas of the inner steel tube, core concrete, and sandwich concrete, respectively.

\section{Finite Element Model}

\subsection{Constitutive Models of Materials}

\subsubsection{Steel Tube}

The constitutive model of the inner and outer steel tubes is separated into two segments in this paper: the elastic segment and the stress hardening segment. The expression of the above segments can be presented as the following Equation (3):

$$
\sigma_{\mathrm{i}}= \begin{cases}E_{\mathrm{s}} \times \varepsilon & \left(\varepsilon \leq \varepsilon_{\mathrm{yk}}\right) \\ f_{\mathrm{yk}}+E_{1} \times\left(\varepsilon-\varepsilon_{\mathrm{yk}}\right) & \left(\varepsilon>\varepsilon_{\mathrm{yk}}\right)\end{cases}
$$

where $E_{\mathrm{S}}$ is the elastic modulus of the inner and outer steel tubes and $E_{1}$, taken as $0.01 E_{\mathrm{s}}$, is the strengthening coefficient of the inner and outer steel tubes entering the stress hardening segment. $\varepsilon_{\mathrm{yk}}$ and $f_{\mathrm{yk}}$ are the yield strain and yield strength of the inner and outer steel tubes, respectively.

\subsubsection{Concrete}

Multiple constitutive models (CMs) for confined concrete have been proposed by many scholars, such as J. B. Mander [11], J. G. Teng [21], M. Pagoulatou [22], and L. H. Han [28], as shown in Figure 3. Additionally, the CM curve of unconfined concrete provided by GB50010-2010 [31] is shown in Figure 3. By comparing the different CMs for confined concrete, L. H. Han's CM was selected in the present paper to simulate the damage state of concrete.

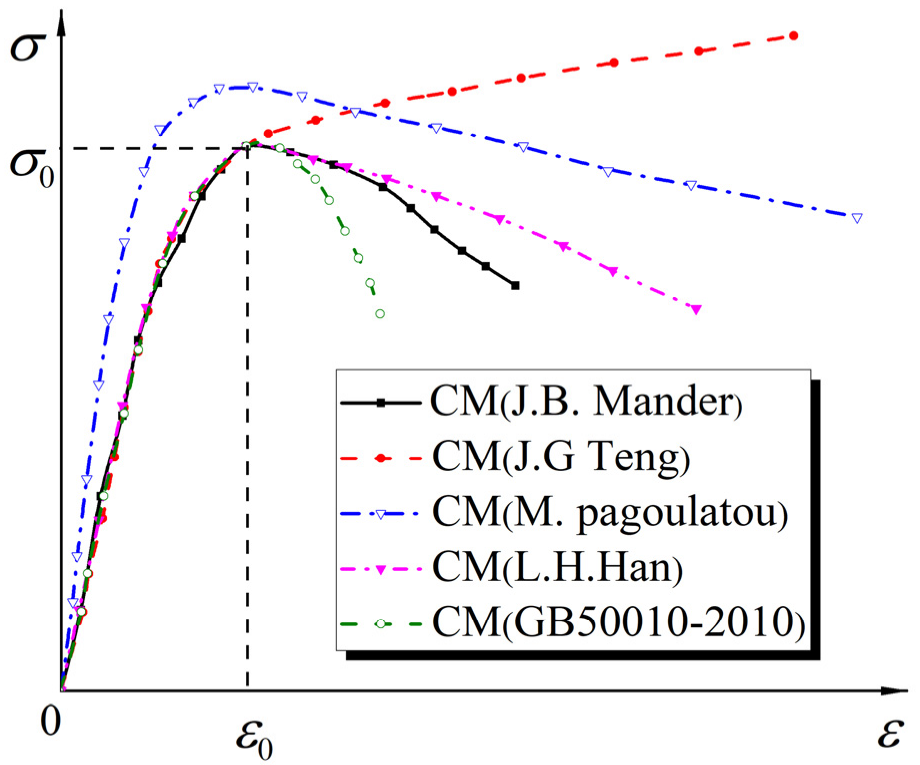

Figure 3. Nonlinear CMs for concrete. 


\subsection{Element Type and Contact Mode}

The finite element model of the CFDST specimens was established using ABAQUS software. The eight-node three-dimensional solid element (C3D8R) was adopted to simulate the steel tubes and concrete. The interfacial contact between the steel tubes and concrete consisted of hard contact in a normal direction and friction contact in a tangent direction. It would be possible for the interface between the steel tube and concrete to transfer the shear stress $(\tau)$ [32], if $\tau$ was not greater than the critical value of the interface bond stress $\left(\tau_{\text {bond }}\right)$. On the contrary, the relative slip would occur between the steel tube and concrete if $\tau$ was greater than $\tau_{\text {bond, }}$ as shown in Equation (4). The relative slip between the steel tube and concrete is considered in the present paper. The interfacial contact of the CFDST specimens is shown in Figure 4:

$$
\tau=\mu p\left\{\begin{array}{lr}
\leq \tau_{\text {bond }} & (\text { coordination deformation) } \\
>\tau_{\text {bond }} & \text { (relative slip) }
\end{array}\right.
$$

where $p$ represented the pressure of interfacial contact, and $\mu$ is the friction coefficient, which takes the value of 0.5 [33].

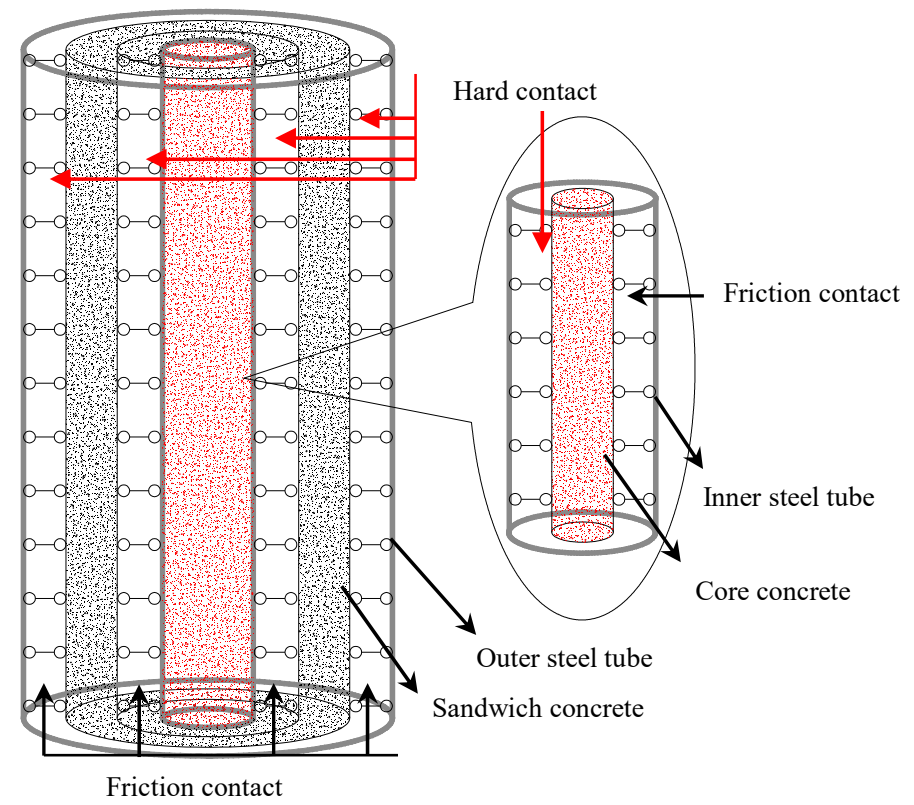

Figure 4. Interfacial contact of the CFDST stub columns.

\subsection{Boundary Condition and Mesh}

The two reference points (RP1 and RP2) were established with the distance of $10 \mathrm{~mm}$ outward from two ends, respectively. In order to ensure that specimens could be subjected to a uniform axial compression load, RP1 and RP2 were coupled with the top and bottom surfaces of the specimens, respectively. Both displacements and rotations of RP2 were constrained to realize the consolidation for the bottom surface of the CFDST stub columns, which could restrict the displacements of the $X, Y$, and $Z$ directions $\left(U_{1}, U_{2}\right.$, and $\left.U_{3}\right)$, as well as the rotations of the $X, Y$, and $Z$ directions $\left(U R_{1}, U R_{2}\right.$, and $\left.U R_{3}\right)$. The vertical displacement was applied to the RP1 point of the specimens. During the process of assembly, the models were divided into four equal parts along the circular section. In order to guarantee the mesh quality and calculation accuracy, each component should be divided into 3 layers in the lateral direction, at least. As for the mesh size (MS) of the concrete, the difference should not be too great in the three directions. It can be suggested that the shape of the element mesh should be a hexahedron, and the mesh and boundary conditions are shown in Figure 5: 


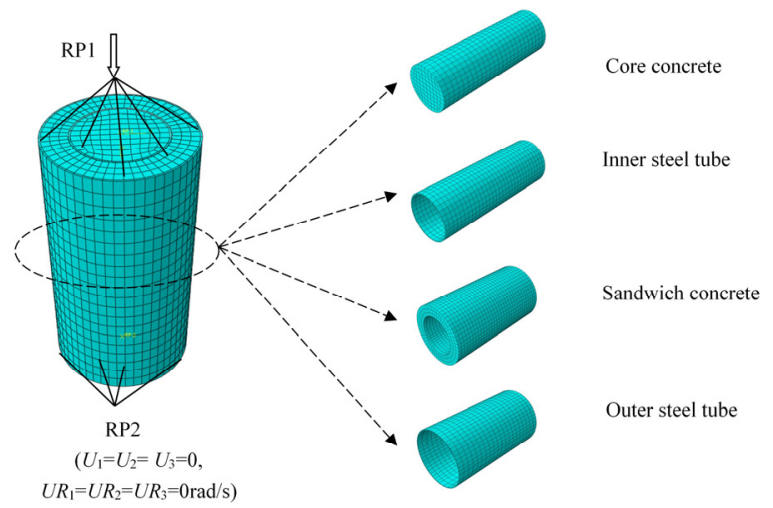

Figure 5. Mesh and boundary condition of the CFDST stub columns.

\section{Experimental Verification}

\subsection{Existing Test Review}

To verify the rationality of the modeling method developed in this paper, 26 similar experimental specimens [24,25] were selected, and 26 corresponding FE specimens were carried out based on the above modeling method. The dimensions and material properties of the experimental specimens are summarized in Table 2. The meshing had a significant impact on the results of the finite element calculation, so it was necessary to adopt a suitable mesh size. Firstly, perform a calculation using a large mesh size, and subsequently conduct the calculation again using half of the original mesh size. By comparing the results of the two calculations, if the calculation error is within $2 \%$, the mesh size can be regarded as meeting the requirements. Otherwise, the mesh should continue to be subdivided until the requirements are met. Taking the CC1-SC1-OT1 specimen as an example, the comparisons of modeling using different mesh sizes is shown in Figure 6. From the comparisons between the simulations and experiments, it was found in Figure 6 that it was better simulate $20 \mathrm{~mm}$ as the mesh size. In this paper, the average mesh size for the concrete and steel tubes of the reduced-scale specimens was $20 \mathrm{~mm}$, while that of the full-scale specimens was $50 \mathrm{~mm}$.

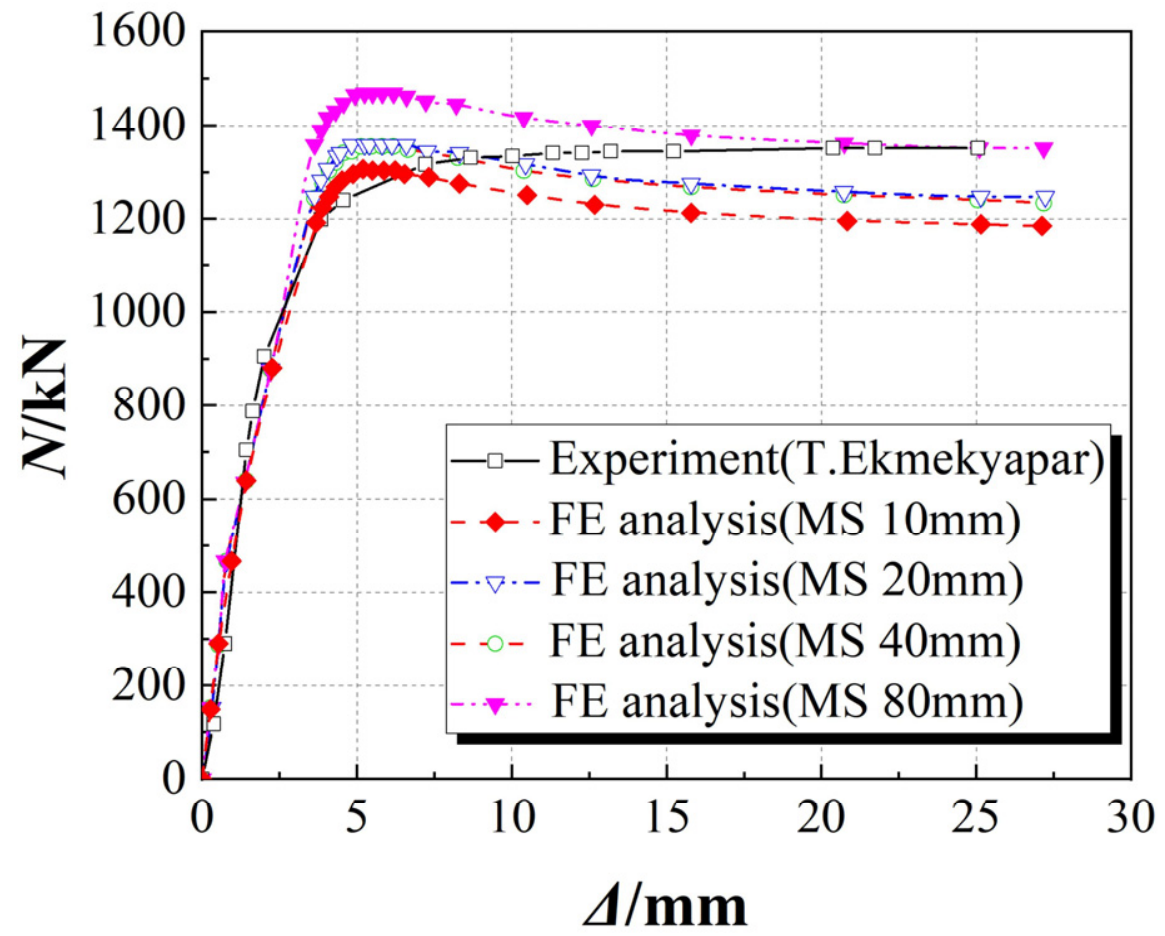

Figure 6. Comparison of different mesh sizes for the CC1-SC1-OT1 specimen. 
Table 2. The specific parameters of the existing specimens.

\begin{tabular}{|c|c|c|c|c|c|c|c|c|}
\hline Specimens & $D_{\mathrm{i}} \times t_{\mathrm{i}} \times \underset{/ \mathrm{mm}^{5}}{t_{\mathrm{o}}} \times D_{\mathrm{o}} \times h$ & $\underset{/ \mathrm{MPa}}{f_{\mathrm{ci}}}$ & $\underset{\mathrm{MPa}}{f_{\mathrm{yi}}}$ & $\underset{/ \mathrm{MPa}}{f_{\mathrm{co}}}$ & $\underset{\text { /MPa }}{f_{\text {yo }}}$ & $\begin{array}{c}N_{\mathrm{u}}^{\mathrm{T}} \\
/ \mathrm{kN}\end{array}$ & $\begin{array}{c}N_{\mathrm{u}}^{\mathrm{s}} \\
/ \mathrm{kN}\end{array}$ & $\frac{\left|N_{\mathrm{u}}^{\mathrm{s}}-N_{\mathrm{u}}^{\mathrm{T}}\right|}{N_{\mathrm{u}}^{\mathrm{T}}} \mid \%$ \\
\hline \multicolumn{9}{|c|}{ T. Ekmekyapar's tests [25] } \\
\hline CC1-SC1-OT1 & $88.9 \times 4.25 \times 3.3 \times 139.7 \times 270$ & 30.55 & 375 & 30.55 & 290 & 1435.05 & 1372.34 & 4.37 \\
\hline CC1-SC1-OT2 & $88.9 \times 4.25 \times 5.87 \times 139.7 \times 270$ & 30.55 & 375 & 30.55 & 355 & 1977.94 & 1948.44 & 1.49 \\
\hline CC1-SC2-OT1 & $88.9 \times 4.25 \times 3.3 \times 139.7 \times 270$ & 30.55 & 375 & 68.09 & 290 & 1606.98 & 1657.31 & 3.13 \\
\hline CC2-SC1-OT2 & $88.9 \times 4.25 \times 5.87 \times 139.7 \times 270$ & 68.09 & 375 & 30.55 & 355 & 2153.11 & 2153.44 & 0.02 \\
\hline CC1-SC2-OT2 & $88.9 \times 4.25 \times 5.87 \times 139.7 \times 270$ & 30.55 & 375 & 68.09 & 355 & 2044.44 & 1999.27 & 2.21 \\
\hline CC2-SC2-OT1 & $88.9 \times 4.25 \times 3.3 \times 139.7 \times 270$ & 68.09 & 375 & 68.09 & 290 & 1561.73 & 1574.47 & 0.82 \\
\hline CC2-SC2-OT2 & $88.9 \times 4.25 \times 5.87 \times 139.7 \times 270$ & 68.09 & 375 & 68.09 & 355 & 2567.9 & 2695.21 & 4.96 \\
\hline CC2-SC1-OT1 & $88.9 \times 4.25 \times 3.3 \times 139.7 \times 270$ & 68.09 & 375 & 30.55 & 290 & 1570.15 & 1656.44 & 5.49 \\
\hline \multicolumn{9}{|c|}{ X.D. Fang's tests [24] } \\
\hline S1 & $102 \times 8 \times 8 \times 219 \times 880$ & 30.4 & 331.3 & 30.4 & 325 & 5052.63 & 4877.82 & 3.46 \\
\hline $\mathrm{S} 2$ & $102 \times 6 \times 6 \times 219 \times 880$ & 30.4 & 321.7 & 30.4 & 312.5 & 4139.34 & 3929.36 & 5.07 \\
\hline S3 & $102 \times 4.5 \times 6 \times 219 \times 880$ & 30.4 & 372.5 & 30.4 & 312.5 & 3606.56 & 3566.10 & 1.12 \\
\hline S4 & $102 \times 8 \times 8 \times 168 \times 680$ & 30.4 & 331.3 & 30.4 & 355 & 4139.34 & 4085.18 & 1.31 \\
\hline S5 & $102 \times 6 \times 6 \times 168 \times 680$ & 30.4 & 321.7 & 30.4 & 365 & 3688.52 & 3474.91 & 5.79 \\
\hline S6 & $102 \times 4.5 \times 6 \times 168 \times 680$ & 30.4 & 372.5 & 30.4 & 365 & 3278.69 & 3086.84 & 5.85 \\
\hline S7 & $102 \times 8 \times 8 \times 219 \times 880$ & 55.77 & 331.3 & 55.77 & 325 & 5080.65 & 5292.76 & 4.17 \\
\hline S9 & $102 \times 4.5 \times 6 \times 219 \times 880$ & 55.77 & 372.5 & 55.77 & 312.5 & 4306.45 & 4152.02 & 3.59 \\
\hline S10 & $102 \times 8 \times 8 \times 168 \times 680$ & 55.77 & 331.3 & 55.77 & 355 & 4274.19 & 4425.74 & 3.55 \\
\hline S12 & $102 \times 4.5 \times 6 \times 168 \times 680$ & 55.77 & 372.5 & 55.77 & 365 & 3467.74 & 3403.40 & 1.86 \\
\hline S13 & $102 \times 8 \times 8 \times 219 \times 880$ & 69.21 & 331.3 & 69.21 & 325 & 5641.03 & 5522.64 & 2.10 \\
\hline S15 & $102 \times 6 \times 6 \times 219 \times 880$ & 69.21 & 321.7 & 69.21 & 312.5 & 4974.36 & 4676.37 & 5.99 \\
\hline S16 & $102 \times 8 \times 8 \times 168 \times 680$ & 69.21 & 331.3 & 69.21 & 355 & 4145.30 & 4328.35 & 4.51 \\
\hline S18 & $102 \times 6 \times 6 \times 168 \times 680$ & 69.21 & 321.7 & 69.21 & 365 & 3931.62 & 3605.05 & 8.31 \\
\hline S21 & $102 \times 8 \times 8 \times 219 \times 880$ & 84.19 & 331.3 & 84.19 & 325 & 5959.24 & 5998.78 & 0.66 \\
\hline $\mathrm{S} 22$ & $102 \times 6 \times 6 \times 219 \times 880$ & 84.19 & 321.7 & 84.19 & 312.5 & 5735.93 & 5179.37 & 9.70 \\
\hline $\mathrm{S} 25$ & $102 \times 8 \times 8 \times 168 \times 680$ & 84.19 & 331.3 & 84.19 & 355 & 4338.84 & 4736.20 & 9.16 \\
\hline S26 & $102 \times 6 \times 6 \times 168 \times 680$ & 84.19 & 321.7 & 84.19 & 365 & 4297.52 & 4108.29 & 4.40 \\
\hline
\end{tabular}

\subsection{Verification Result}

The FE analysis of 26 specimens was carried out by adopting the above modeling method. The $N-\Delta$ curves can be obtained, as shown in Figure 7 . It can be seen that all of the results are in agreement for the majority of the specimens; however, when the specimens are in the plastic stage, the agreement of the results between the FE analysis and the experiment is poor. The reason for this is that the concrete was regarded as an isotropic continuous element during the simulation analysis process, while the concrete belonged to the discrete element in the experiment. The axial compression bearing capacity $\left(N_{\mathfrak{u}}^{\mathrm{T}}\right.$ and $\left.N_{\mathrm{u}}^{\mathrm{s}}\right)$ obtained by experimental means and the FE analysis are shown in Table 2 and Figure 8. The maximum error (Error $_{\text {Max }}$ ) between them was $9.70 \%$, and it can be seen that the simulation accuracy is so great that it can meet the requirements of practical engineering. The failure modes of all specimens were essentially similar to the experiment, and 2 representative specimens (CC2-SC1-OT1 and S7) were given, as shown in Figure 9. 


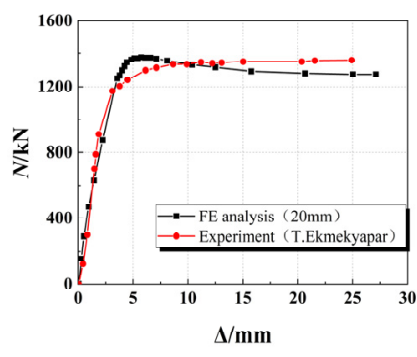

(a) CC1-SC1-OT1

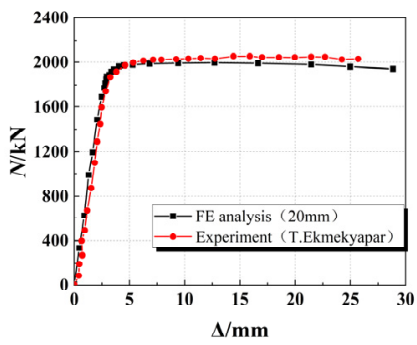

(e) CC1-SC2-OT2

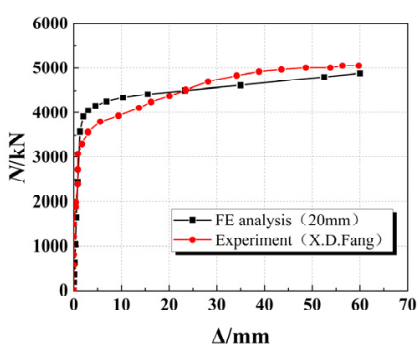

(i) $\mathrm{S1}$

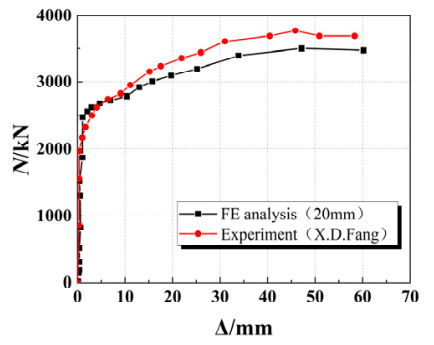

(m) $\mathrm{S} 5$

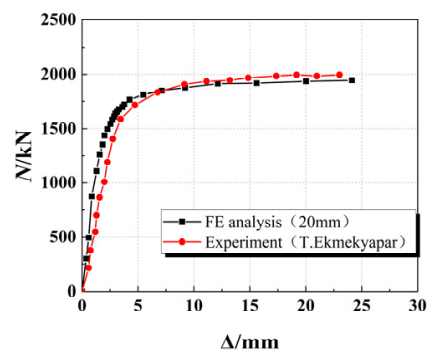

(b) CC1-SC1-OT2

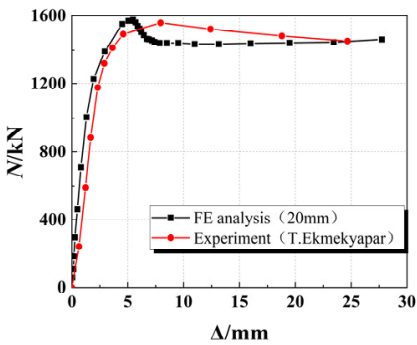

(f) CC2-SC2-OT1

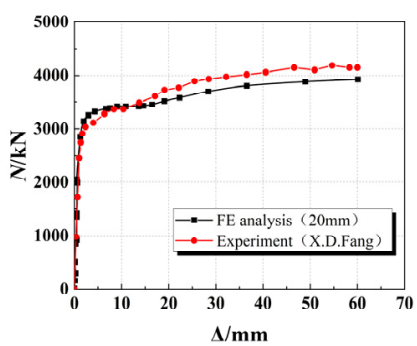

(j) S2

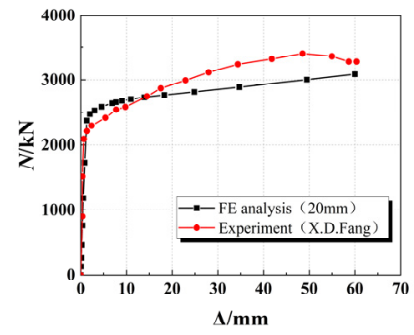

(n) $\mathrm{S} 6$

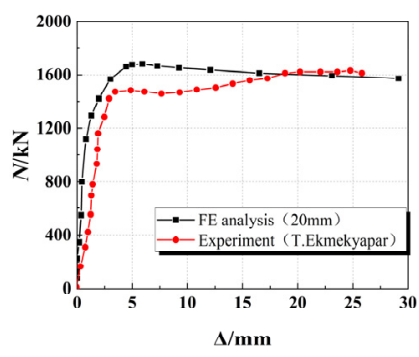

(c) CC1-SC2-OT1

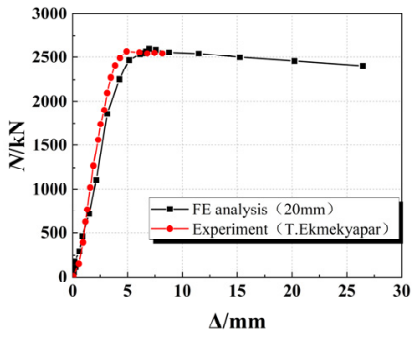

(g) CC2-SC2-OT2

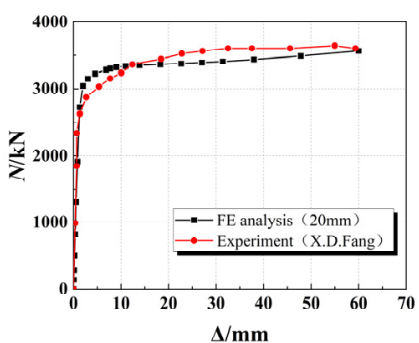

(k) S3

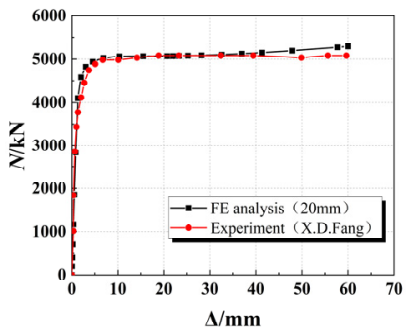

(o) S7

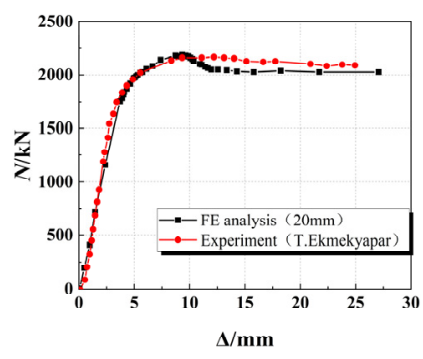

(d) CC2-SC1-OT2

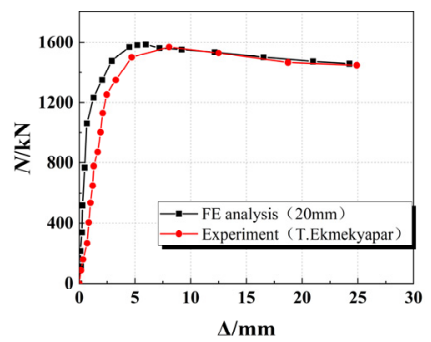

(h) CC2-SC1-OT1

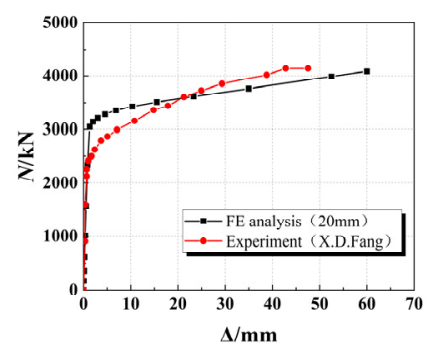

(l) $\mathrm{S4}$

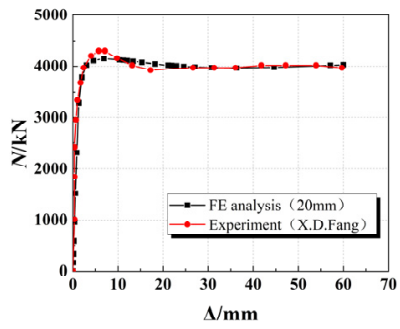

(p) 59

Figure 7. Cont. 


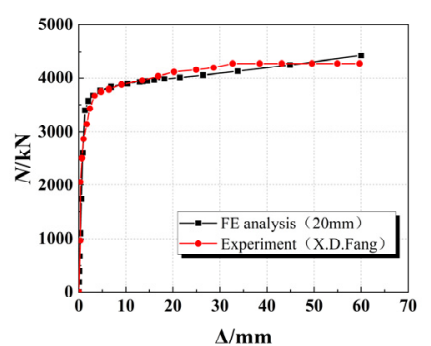

(q) $\mathrm{S} 10$

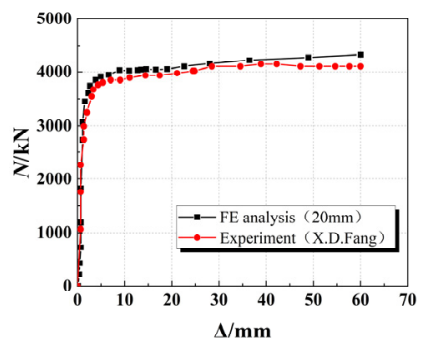

(u) $\mathrm{S} 16$

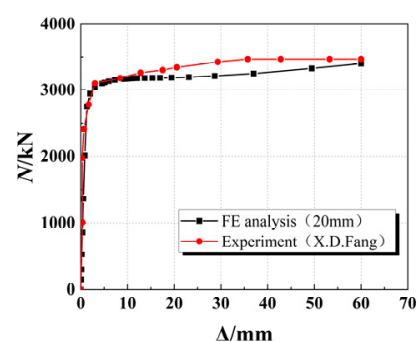

(r) $\mathrm{S} 12$

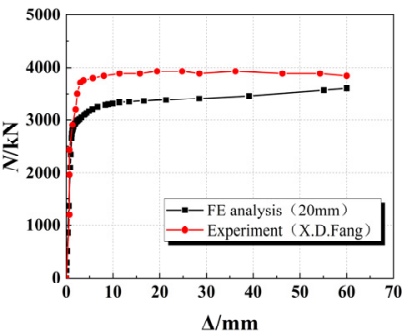

(v) $\mathrm{S} 18$

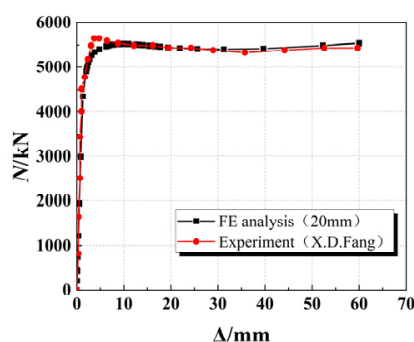

(s) $\mathrm{S} 13$

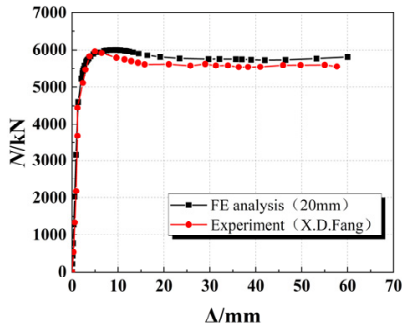

(w) S21

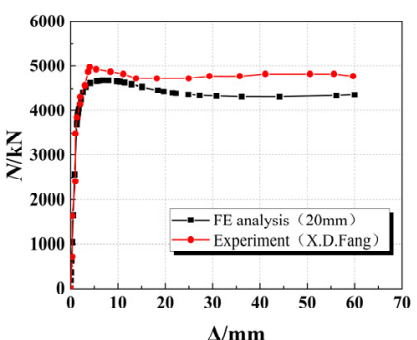

(t) $\mathrm{S} 15$

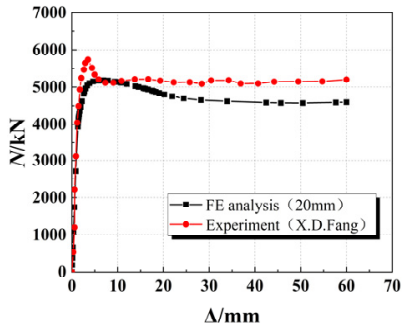

(x) S22

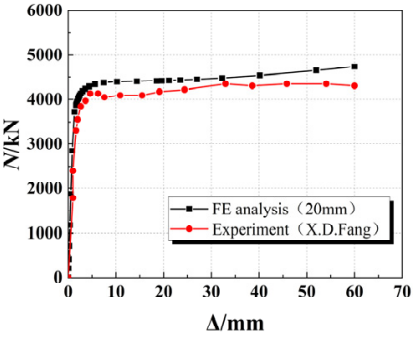

(y) S25

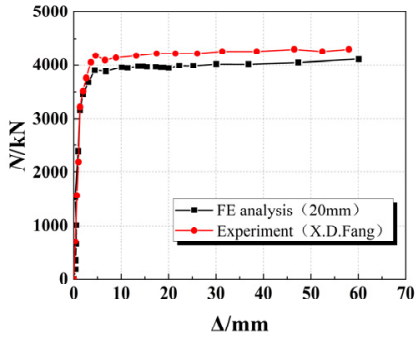

(z) S26

Figure 7. Comparisons between the FE analysis results and experimental curves.

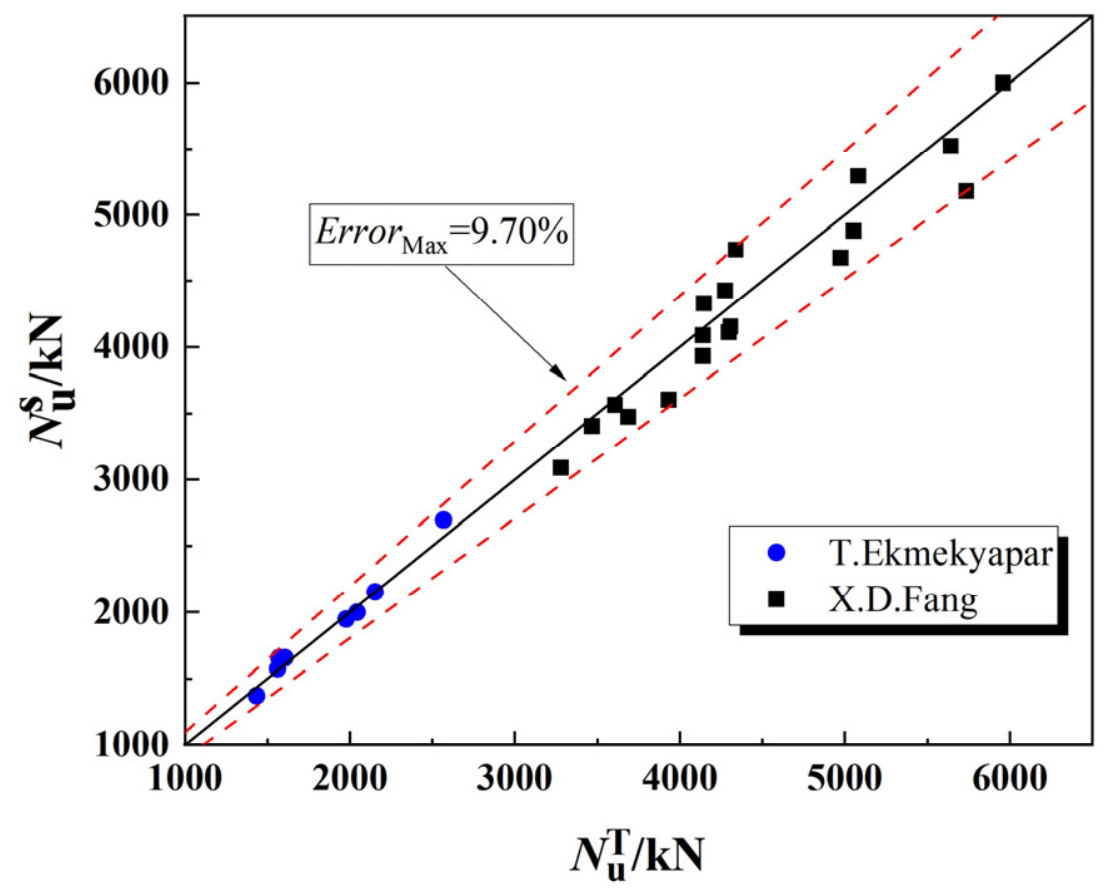

Figure 8. The maximum error between the experimental results and FE results. 


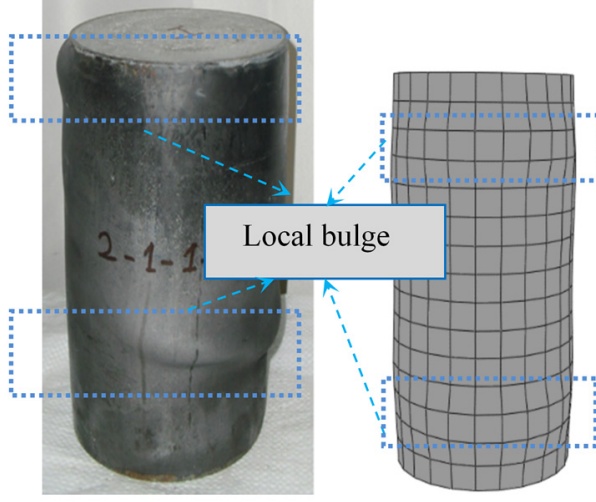

(a)

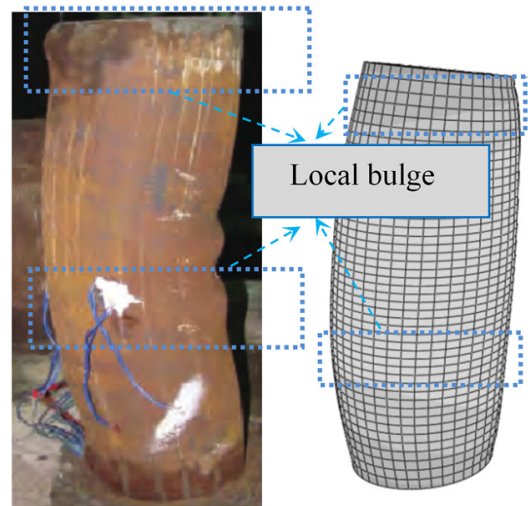

(b)

Figure 9. Comparisons of the failure modes for 2 representative specimens: (a) CC2-SC1-OT1 and (b) S7.

\section{Parameter Analysis}

In order to analyze the effect of different parameters on the axial compression behavior of the test specimens, the $N-\Delta$ curves of specimens with different controlled parameters are listed from Figures 10-14. It can be seen that the trend of the curves of the full-scale specimens is essentially similar, with 21 reduced-scale specimens conducted in the existing literature [34].

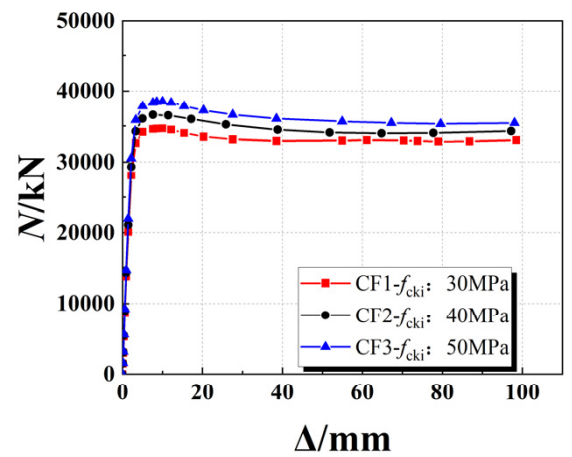

(a)

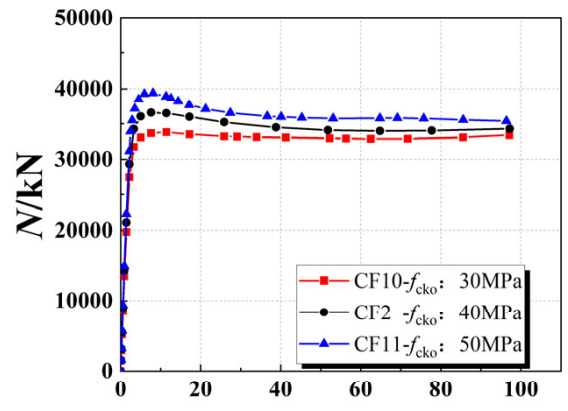

$\Delta / \mathbf{m m}$

(b)

Figure 10. Comparisons of the $N-\Delta$ curves of specimens with different $f_{\text {cki }}$ and $f_{\text {cko }}$ : (a) full-scale specimens with different $f_{\text {cki }}$ and (b) full-scale specimens with different $f_{\text {cko }}$.

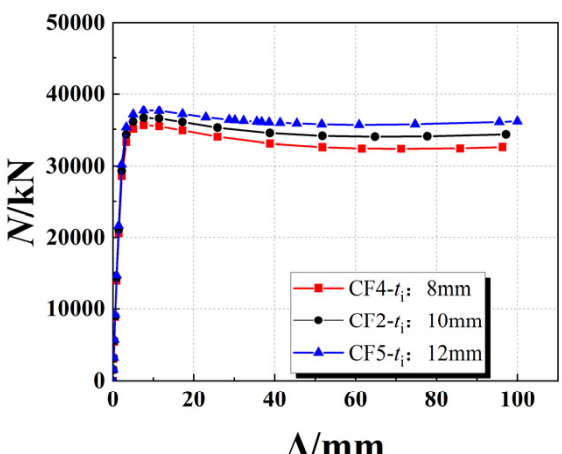

(a)

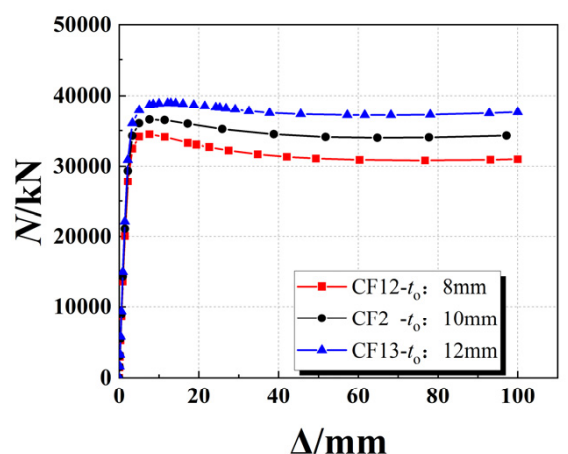

(b)

Figure 11. Comparisons of the $N-\Delta$ curves of specimens with different $t_{\mathrm{i}}$ and $t_{\mathrm{o}}$ : (a) specimens with different $t_{\mathrm{i}}$ and (b) specimens with different $t_{\mathrm{o}}$. 


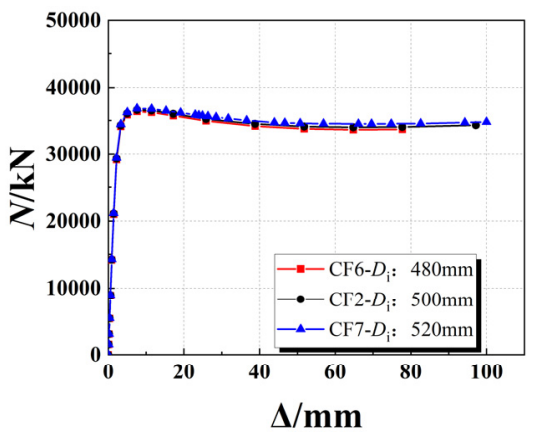

(a)

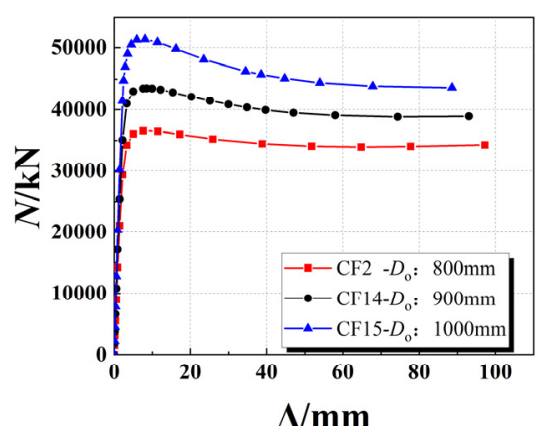

(b)

Figure 12. Comparisons of the $N-\Delta$ curves of specimens with different $D_{\mathrm{i}}$ and $D_{\mathrm{o}}$ : (a) specimens with different $D_{\mathrm{i}}$ and (b) specimens with different $D_{\mathrm{o}}$.

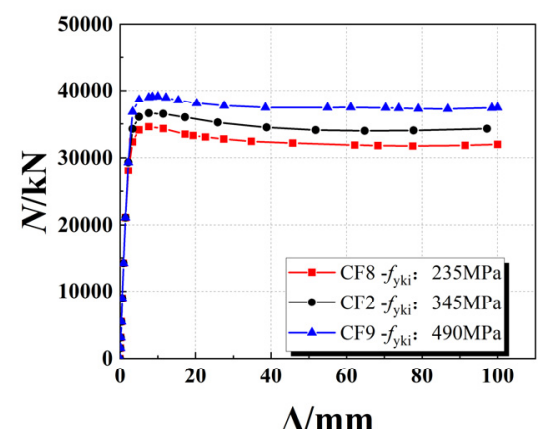

(a)

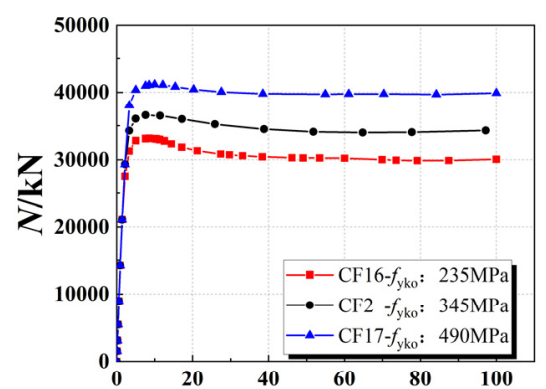

$\Delta / \mathbf{m m}$

Figure 13. Comparisons of the $N-\Delta$ curves of specimens with different $f_{\text {yki }}$ and $f_{\text {yko }}$ : (a) specimens with different $f_{\mathrm{yki}}$ and (b) specimens with different $f_{\mathrm{yko}}$.

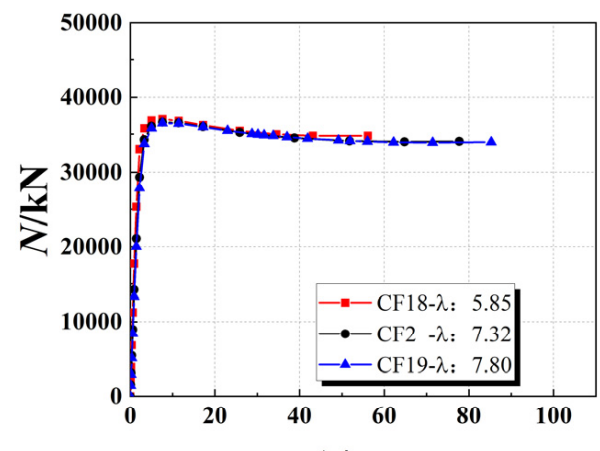

$\Delta / \mathbf{m m}$

Figure 14. Comparisons of the $N-\Delta$ curves of specimens with different $\lambda$.

\subsection{Concrete Strength $\left(f_{\mathrm{cki}}, f_{\mathrm{cko}}\right)$}

The $N-\Delta$ curves of full-scale specimens with different strengths of core concrete $\left(f_{\text {cki }}\right)$ and sandwich concrete $\left(f_{\text {cko }}\right)$ are listed in Figure 10. In Figure 10a, it can be seen that when $f_{\text {cki }}$ is assigned the different values of $30 \mathrm{MPa}, 40 \mathrm{MPa}$, and $50 \mathrm{MPa}$, the $N_{\mathrm{s}}^{\mathrm{u}}$ of full-scale specimens can be improved from $34,671.90 \mathrm{kN}$ to $36,578.70 \mathrm{kN}$ and $38,478.20 \mathrm{kN}$, respectively, which increases by $5.49 \%$ and $10.98 \%$. In Figure $10 \mathrm{~b}$, it can be seen that when $f_{\text {cko }}$ is assigned the different values of $30 \mathrm{MPa}, 40 \mathrm{MPa}$, and $50 \mathrm{MPa}$, the $N_{\mathrm{s}}^{\mathrm{u}}$ of full-scale specimens can be improved from $33,811.60 \mathrm{kN}$ to $36,578.70 \mathrm{kN}$ and $39,392.80 \mathrm{kN}$, respectively, which increases by $7.56 \%$ and $15.26 \%$. Therefore, $N_{\mathrm{s}}^{\mathrm{u}}$ can be improved with the increase in $f_{\text {cki }}$ and $f_{\text {cko, }}$, but it is noted that $f_{\text {cko, }}$, significantly, has a more important impact on improving $N_{\mathrm{s}}^{\mathrm{u}}$ than $f_{\text {cki }}$. 


\subsection{Thickness of the Steel Tubes $\left(t_{\mathrm{i}}, t_{\mathrm{o}}\right)$}

The $N-\Delta$ curves of specimens with different thicknesses of inner $\left(t_{\mathrm{i}}\right)$ and outer $\left(t_{\mathrm{o}}\right)$ steel tubes are listed in Figure 11. In Figure 11a, it can be seen that when $t_{\mathrm{i}}$ is assigned the different values of $8 \mathrm{~mm}$ to $10 \mathrm{~mm}$ and $12 \mathrm{~mm}$, the $N_{\mathrm{s}}^{\mathrm{u}}$ of specimens can be improved from $35,410.30 \mathrm{kN}$ to $36,482.40 \mathrm{kN}$ and $37,625.30 \mathrm{kN}$, respectively, which increases by $3.03 \%$ and $6.26 \%$. In Figure $11 \mathrm{~b}$, it can be seen that when $t_{\mathrm{o}}$ is assigned the different values of $8 \mathrm{~mm}$, $10 \mathrm{~mm}$, and $12 \mathrm{~mm}$, the $N_{\mathrm{s}}^{\mathrm{u}}$ of specimens can be improved from $34,478.00 \mathrm{kN}$ to $36,578.70 \mathrm{kN}$ and $38,930.40 \mathrm{kN}$, respectively, which increases by $6.09 \%$ and $12.91 \%$. Therefore, $N_{\mathrm{s}}^{\mathrm{u}}$ can be improved by increasing $t_{\mathrm{i}}$ and $t_{\mathrm{o}}$. It is noted that $N_{\mathrm{s}}^{\mathrm{u}}$ can be improved by $t_{\mathrm{o}}$ more significantly than $t_{\mathrm{i}}$.

\subsection{Diameters of the Core and Sandwich Concrete $\left(D_{\mathrm{i}}, D_{\mathrm{o}}\right)$}

The $N-\Delta$ curves of the specimens with different diameters of core concrete $\left(D_{\mathrm{i}}\right)$ and sandwich concrete $\left(D_{\mathrm{o}}\right)$ are listed in Figure 12. In Figure 12a, it can be seen that the increase in $D_{\mathrm{i}}$ has little influence on improving $N_{\mathrm{s}}^{\mathrm{u}}$; on the contrary, the load-holding behavior of the CFDST can be significantly improved. In Figure $12 \mathrm{~b}$, it can be seen that when $D_{\mathrm{o}}$ is assigned the different values of $800 \mathrm{~mm}, 900 \mathrm{~mm}$, and $1000 \mathrm{~mm}$, the $N_{\mathrm{s}}^{\mathrm{u}}$ of the specimens can be improved from $36,578.70 \mathrm{kN}$ to $43,521.30 \mathrm{kN}$ and $51,334.50 \mathrm{kN}$, respectively, which increases by $18.98 \%$ and $40.34 \%$. Therefore, $N_{\mathrm{s}}^{\mathrm{u}}$ can be improved more significantly by increasing $D_{0}$, while the ductility gradually decreases with the increase in $D_{0}$, and the performance is similar to the CFST columns.

\subsection{Strength of the Steel Tubes $\left(f_{\mathrm{yki}}, f_{\mathrm{yko}}\right)$}

The $N-\Delta$ curves of specimens with different strengths of the inner steel tubes $\left(f_{\mathrm{yki}}\right)$ and outer steel tubes $\left(f_{\text {yko }}\right)$ are listed in Figure 13. In Figure 13a, it can be seen that when $f_{\text {yki }}$ is assigned the different values of $235 \mathrm{MPa}, 345 \mathrm{MPa}$, and $490 \mathrm{MPa}$, the $N_{\mathrm{s}}^{\mathrm{u}}$ of specimens can be improved from $34,596.20 \mathrm{kN}$ to $36,578.70 \mathrm{kN}$ and $39,105.00 \mathrm{kN}$, respectively, which increases by $5.73 \%$ and $13.03 \%$. In Figure $13 \mathrm{~b}$, it can be seen that when $f_{\text {yko }}$ is assigned the different values of $235 \mathrm{MPa}, 345 \mathrm{MPa}$, and $490 \mathrm{MPa}$, the $N_{\mathrm{s}}^{\mathrm{u}}$ of specimens can be improved from $33,148.20 \mathrm{kN}$ to $36,578.70 \mathrm{kN}$ and $41,168.10 \mathrm{kN}$, respectively, which increases by $10.35 \%$ and $24.19 \%$. Therefore, $N_{\mathrm{s}}^{\mathrm{u}}$ can be improved by increasing $f_{\mathrm{yki}}$ and $f_{\mathrm{yko}}$. It is noted that $f_{\mathrm{yko}}$ can improve $N_{\mathrm{s}}^{\mathrm{u}}$ more significantly than $f_{\mathrm{yki}}$.

\subsection{Slenderness Ratio $(\lambda)$}

The $N-\Delta$ curves of specimens with different slenderness ratios $(\lambda)$ are listed in Figure 14. It can be seen from Figure 14 that when $\lambda$ is assigned the different values of $5.85,7.32$, and 7.80, the $N_{\mathrm{s}}^{\mathrm{u}}$ of specimens decreases from $36,978.60 \mathrm{kN}$ to $36,578.70 \mathrm{kN}$ and to $36,465.80 \mathrm{kN}$, respectively, which decreases by $1.08 \%$ and $1.39 \%$. On the contrary, the ultimate displacement increases from $56.12 \mathrm{~mm}$ to $77.75 \mathrm{~mm}$ and to $85.28 \mathrm{~mm}$, and the growth rate is $38.54 \%$ and $51.96 \%$, respectively. Therefore, $N_{\mathrm{s}}^{\mathrm{u}}$ decreases gradually with the increase in $\lambda$, but the ultimate displacement significantly improves.

\section{Stress Mechanism of the CFDST Stub Columns}

\subsection{Stress Distribution and Deformation Process}

When the specimens are subjected to longitudinal pressure $(N)$, the longitudinal strain $\left(\varepsilon_{3}\right)$ of symmetrical CFDST stub columns increases gradually with the increase in $N$, and the relationship between the radial strains and longitudinal strains can be expressed in the form of Equation (5):

$$
\left\{\begin{array}{l}
\varepsilon_{\mathrm{s}}^{\prime}=\mu_{\mathrm{s}} \varepsilon_{3} \\
\varepsilon_{\mathrm{c}}^{\prime}=\mu_{\mathrm{c}} \varepsilon_{3}
\end{array}\right.
$$

where $\mu_{\mathrm{s}}$ and $\mu_{\mathrm{c}}$ are the Poisson's ratios of the steel tubes and concrete, respectively. $\varepsilon_{\mathrm{s}}^{\prime}$ and $\varepsilon_{\mathrm{c}}^{\prime}$ are the radial strain of the steel tubes and concrete, respectively. 
The Poisson's ratios of the steel tubes and concrete will continuously change during the loading process. Initially, $\mu_{\mathrm{c}}<\mu_{\mathrm{s}}$, so $\varepsilon_{\mathrm{s}}^{\prime}$ is greater than $\varepsilon_{\mathrm{C}^{\prime}}^{\prime}$ and it is impossible for the steel tubes to provide a constraint effect for the concrete. When the longitudinal compression stress of the steel tubes reaches its proportional limit (i.e., $\delta_{3} \approx f_{p}$ ), $\mu_{\mathrm{c}}$ approximately equals $\mu_{\mathrm{s}}$, so $\varepsilon_{\mathrm{s}}^{\prime}$ approximately equals $\varepsilon_{\mathrm{c}}^{\prime}$. When $\mathrm{N}$ gradually increases, $\mu_{\mathrm{c}}>\mu_{\mathrm{s}}$, that is, $\varepsilon_{\mathrm{s}}^{\prime}$ is smaller than $\varepsilon_{\mathrm{c}}^{\prime}$. The lateral expansion of the concrete is constrained by the steel tubes, and it means that the constraint effects are functioned. The stress distribution of the symmetrical CFDST stub columns is shown in Figure $15 \mathrm{a}$, where $f_{\mathrm{li}}$ and $f_{\mathrm{lo}}$ are the radial pressures provided by the core and sandwich concrete, respectively. Both $f_{\text {so }}{ }^{\mathrm{c}}$ and $f_{\mathrm{si}}{ }^{\mathrm{c}}$ are the circumferential forces provided by the inner and outer steel tubes, as shown in Equation (6). Both steel tubes and concrete are under the state of tri-axial compression stress. The longitudinal, radial, and circumferential stresses $\left(\delta_{3}, \delta_{2}, \delta_{1}, \delta_{3}^{\prime}, \delta_{2}^{\prime}\right.$, and $\left.\delta_{1}^{\prime}\right)$ of the inner and outer steel tubes and concrete are presented in Figure $15 \mathrm{~b}$ as the following:

$$
\left\{\begin{array}{l}
f_{\mathrm{si}}^{\mathrm{c}}=E_{\mathrm{si}}^{\mathrm{c}} \varepsilon_{\mathrm{si}}^{\mathrm{c}} t_{\mathrm{i}} \\
f_{\mathrm{so}}^{\mathrm{c}}=E_{\mathrm{so}}^{\mathrm{c}} \varepsilon_{\mathrm{so}}^{\mathrm{c}} t_{\mathrm{o}}
\end{array}\right.
$$

where $\varepsilon_{\mathrm{si}}^{\mathrm{c}}$ and $E_{\mathrm{si}}^{\mathrm{c}}$ are the circumferential strain and the elastic modulus of the inner steel tubes, respectively. Both $\varepsilon_{\mathrm{so}}^{\mathrm{c}}$ and $E_{\mathrm{so}}^{\mathrm{c}}$ are the circumferential strain and elastic modulus of the outer steel tubes, respectively.

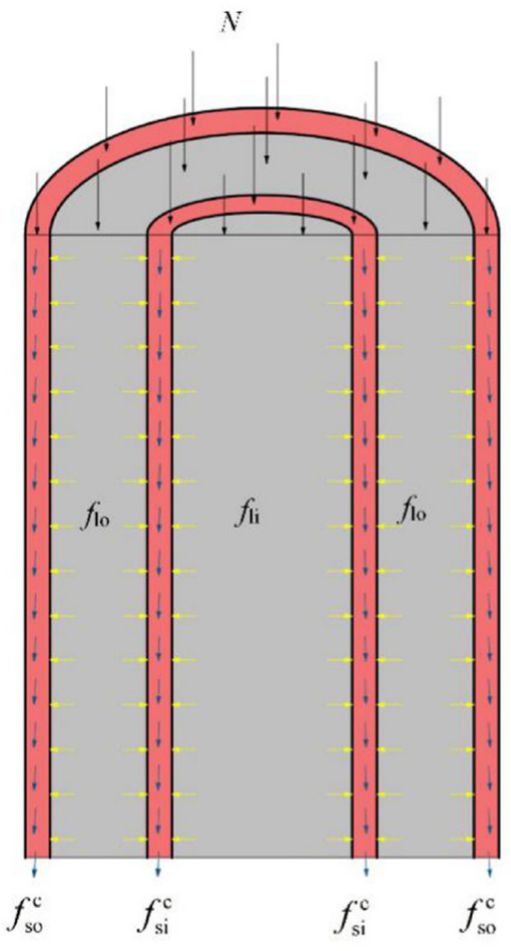

(a)

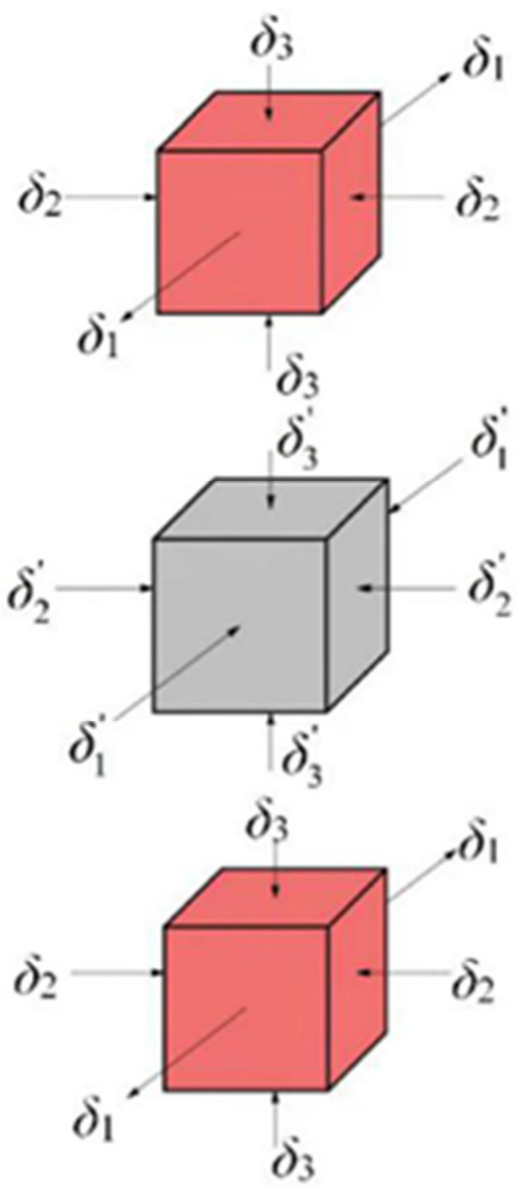

(b)

\section{Outer steel tube}

\section{Concrete}

\section{Inner steel tube}

Figure 15. Stress distribution of the CFDST specimens: (a) profile section and (b) the state of tri-axial stress of the tiny element. 


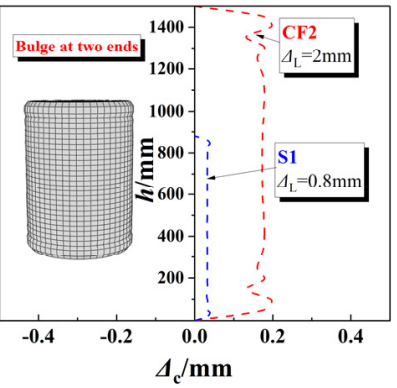

(a)

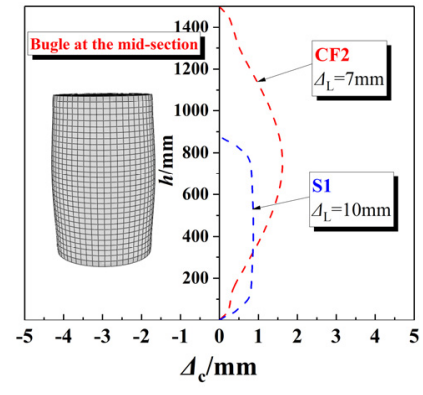

(b)

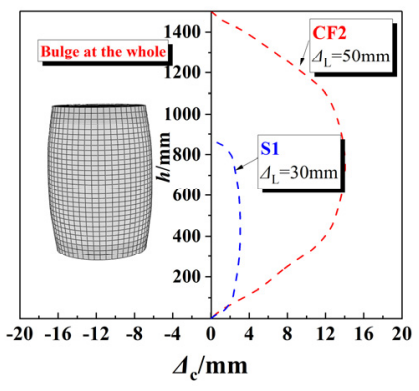

(c)

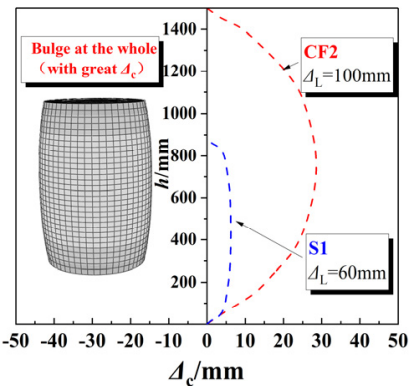

(d)

Figure 16. Deformation process of $\mathrm{S} 1$ and $\mathrm{CF} 2$ : (a) bulge at two ends for specimens; (b) bulge at the mid-section for specimens; (c) bulge at the whole for specimens; and (d) bulge at the whole with great $\Delta_{\mathrm{c}}$ for specimens.

\section{The Expression of the Axial Compression Bearing Capacity}

Research on the reduced-scale CFST stub columns had been widely conducted by domestic and foreign experts, and the calculation formula of the bearing capacity of the CFST stub columns was proposed. In order to verify the applicability of the bearing capacity calculation formula, based on the reduced-scale models, to full-scale specimens, different formulas are used to calculate the bearing capacity of 19 full-scale specimens designed in this paper.

The study on the bearing behavior of hollow CFDST specimens is carried out by adopting the ultimate equilibrium method [23], and the calculation expression of the axial compression bearing capacity $\left(N_{\mathrm{u}}^{\mathrm{c} 1}\right)$ is obtained by introducing the constraint effect coefficient $(\xi)$, as shown in Equation (7):

$$
N_{\mathrm{u}}^{\mathrm{c} 1}=A_{\mathrm{c}} f_{\mathrm{c}}\left(1+\xi^{0.5}+\xi\right)+T\left(A_{\mathrm{so}} f_{\mathrm{syo}}+A_{\mathrm{si}} f_{\mathrm{syi}}\right)
$$

where $A_{\mathrm{c}}, A_{\mathrm{so}}$, and $A_{\mathrm{si}}$ are the areas of the sandwich concrete, outer steel tube, and inner steel tube, respectively; $f_{\mathrm{c}}, f_{\mathrm{syo}}$, are $f_{\text {syi }}$ are the strengths of the sandwich concrete, outer steel tube, and inner steel tube, respectively; $\xi$ is the index of confinement; and $T$ is the hollow ratio of section.

The expression of the axial compression bearing capacity $\left(N_{\mathrm{u}}^{\mathrm{c}}\right)$ for the CFDST mediumlong columns is established by introducing the constraint effect coefficients $\left(\theta_{1}\right.$ and $\left.\theta_{2}\right)$ [24], as shown in Equation (8):

$$
N_{\mathrm{u}}^{\mathrm{c} 2}=A_{\mathrm{c} 1} f_{\mathrm{c} 1}\left(1+1.65 \theta_{1}\right)+A_{\mathrm{c} 2}\left\{f_{\mathrm{c} 2}\left[1+1.65\left(\theta_{1}+\theta_{2}\right)\right]-f_{\mathrm{c} 1}\left(1+1.65 \theta_{1}\right)\right\}
$$

where $A_{\mathrm{c} 1}$ and $A_{\mathrm{c} 2}$ are the areas of the sandwich concrete and core concrete, respectively. $f_{\mathrm{c} 1}$ and $f_{\mathrm{c} 2}$ are the strengths of the sandwich concrete and core concrete, respectively. $\theta_{1}$ 
and $\theta_{2}$ are the indexes for the confinement of the outer steel tube on the sandwich concrete and the outer steel tube as well as the inner steel tube on the core concrete, respectively.

The numerical simulation analysis of reduced-scale CFDST stub columns was conducted using ABAQUS software [34]. By introducing the constraint effect coefficient $\left(\xi_{\mathrm{i}}, \xi_{\mathrm{o}}\right)$ of the inner and outer steel tubes, the expression of the axial compression bearing capacity $\left(N_{\mathrm{u}}^{\mathrm{c} 3}\right)$ of the CFDST stub columns was established, as shown in Equation (9):

$$
N_{\mathrm{u}}^{\mathrm{c} 3}=A_{\mathrm{co}} f_{\mathrm{cko}}\left(1+1.65 \xi_{\mathrm{o}}\right)+A_{\mathrm{ci}} f_{\mathrm{cki}}\left(-4.37 \xi_{\mathrm{o}}+4.12 \xi_{\mathrm{i}}^{0.69}\right)+\left(A_{\mathrm{si}} f_{\mathrm{yki}}+A_{\mathrm{so}} f_{\mathrm{yko}}\right)
$$

where $A_{\mathrm{co}}, A_{\mathrm{ci}}, A_{\mathrm{si}}$, and $A_{\mathrm{so}}$ are the areas of sandwich concrete, core concrete, inner steel tube, and outer steel tube, respectively. $f_{\mathrm{cko}}, f_{\mathrm{cki}}, f_{\mathrm{yki}}$, and $f_{\mathrm{yko}}$ are the strengths of the sandwich concrete, core concrete, inner steel tube, and outer steel tube, respectively. $\xi_{0}$ and $\xi_{\mathrm{i}}$ are the indexes for the confinement of the outer steel tube on the sandwich concrete and outer steel tube, as well as the inner steel tube on the core concrete, respectively.

The axial compression bearing capacity values $\left(N_{\mathrm{u}}^{\mathrm{c} 1}, N_{\mathrm{u}}^{\mathrm{c} 2}, N_{\mathrm{u}}^{\mathrm{c} 3}\right)$ of 19 specimens were calculated using Equations (7)-(9), respectively, and the results $\left(N_{\mathrm{u}}^{\mathrm{s}}\right)$ were compared with those obtained using the finite element calculation, as shown in Figure 17.

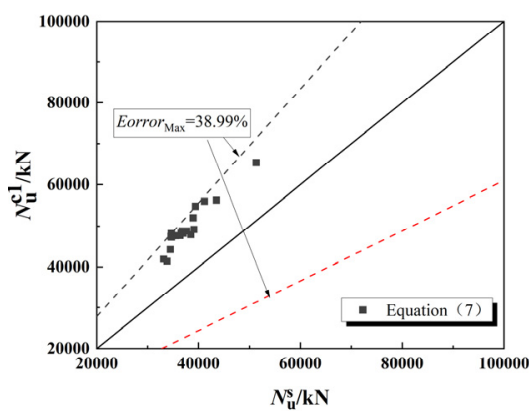

(a)

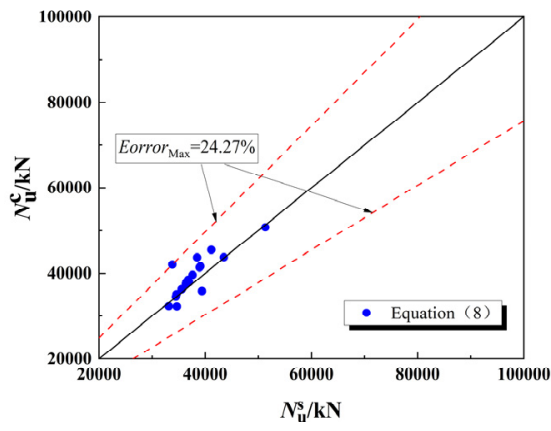

(b)

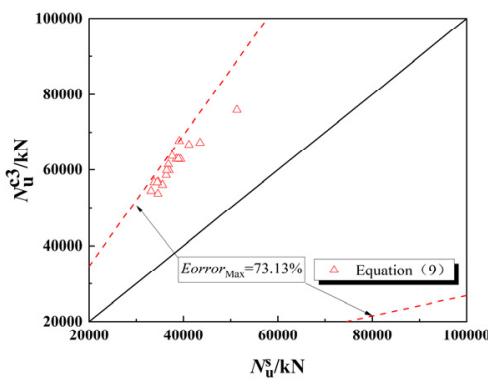

(c)

Figure 17. Comparisons between $N_{\mathrm{u}}^{\mathrm{c}}$ and $N_{\mathrm{u}}^{\mathrm{s}}$ of specimens: (a) $N_{\mathrm{u}}^{\mathrm{c} 1}$ calculated using Equation (7); (b) $N_{\mathrm{u}}^{\mathrm{c} 2}$ calculated using Equation (8); and (c) $N_{\mathrm{u}}^{\mathrm{c} 3}$ calculated using Equation (9).

It can be seen from Figure 17 that the calculation formula for the axial compression bearing capacity of the CFDST stub columns, based on the reduced-scale models, has a great risk for error when applyied to the calculation of symmetrical full-scale specimens. Compared with the finite element calculation results $\left(N_{\mathrm{u}}^{\mathrm{s}}\right)$, the maximum errors among $N_{\mathrm{u}}{ }^{\mathrm{c} 1}, N_{\mathrm{u}} \mathrm{c}$, and $N_{\mathrm{u}}^{\mathrm{c} 3}$ are $38.99 \%, 24.27 \%$, and $73.13 \%$, respectively. The results show that although the full-scale specimens and the reduced-scale specimens have the same stress mechanism and deformation characteristics, considering the influence of size effect, the calculation formula of the axial compression bearing capacity, based on the reduced-scale model, cannot be directly used for the calculation of full-scale specimens, which needs to be adjusted.

In order to obtain more full-scale specimens to regress the calculation formula for the ultimate bearing capacity of symmetrical full-scale CFDST composite stub columns, based on the above 19 full-scale specimens, 33 similar full-scale specimens are supplemented by the above modeling method in this paper. The specific parameters of 42 specimens are shown in Table 3. 
Table 3. The specific parameters of $N_{\mathrm{u}}^{\mathrm{c} 4}$ and $N_{\mathrm{u}}^{\mathrm{s}}$ of 42 specimens.

\begin{tabular}{lcccccc}
\hline Specimens & $\boldsymbol{\lambda}$ & $\boldsymbol{\xi}_{\mathbf{i}}$ & $\boldsymbol{\xi}_{\mathbf{o}}$ & $\begin{array}{c}\boldsymbol{N}_{\mathbf{u}}^{\mathbf{c}} \\
/ \mathbf{k N}\end{array}$ & $\begin{array}{c}\boldsymbol{N}_{\mathbf{u}}^{\mathbf{s}} \\
\mathbf{k N}\end{array}$ & $\begin{array}{c}\left|\boldsymbol{N}_{\mathbf{u}}^{\mathbf{s}}-N_{\mathbf{u}}^{\mathbf{c}}\right| \\
\boldsymbol{N}_{\mathbf{u}}^{\mathbf{s}}\end{array}$ \\
\hline CF1 & 7.32 & 1.61 & 0.44 & $34,671.90$ & $34,503.33$ & 0.49 \\
CF2 & 7.32 & 1.39 & 0.44 & $36,578.70$ & $36,522.32$ & 0.15 \\
CF3 & 7.32 & 1.26 & 0.44 & $38,478.20$ & $38,541.32$ & 0.16 \\
CF4 & 7.32 & 1.25 & 0.44 & $35,564.60$ & $35,511.05$ & 0.15 \\
CF5 & 7.32 & 1.53 & 0.44 & $37,625.30$ & $37,541.47$ & 0.22 \\
CF6 & 7.32 & 1.38 & 0.44 & $36,348.90$ & $36,422.58$ & 0.20 \\
CF7 & 7.32 & 1.41 & 0.44 & $36,801.10$ & $36,621.72$ & 0.49 \\
CF5 & 7.32 & 1.18 & 0.44 & $34,596.20$ & $34,693.72$ & 0.28 \\
CF9 & 7.32 & 1.67 & 0.44 & $39,105.00$ & $38,932.76$ & 0.44 \\
CF10 & 7.32 & 1.63 & 0.58 & $33,811.60$ & $33,696.29$ & 0.34 \\
CF11 & 7.32 & 1.25 & 0.35 & $39,392.80$ & $39,378.49$ & 0.04 \\
CF12 & 7.35 & 1.26 & 0.35 & $34,478.00$ & $34,237.44$ & 0.70 \\
CF13 & 7.28 & 1.52 & 0.53 & $38,930.40$ & $38,817.57$ & 0.29 \\
CF14 & 6.52 & 1.23 & 0.39 & $43,521.30$ & $43,583.51$ & 0.14 \\
CF15 & 5.88 & 1.14 & 0.35 & 51334.50 & $51,254.24$ & 0.16 \\
CF16 & 7.32 & 1.16 & 0.30 & $33,148.20$ & $32,909.31$ & 0.72 \\
CF17 & 7.32 & 1.69 & 0.62 & $41,168.10$ & 41284.93 & 0.28 \\
CF18 & 5.85 & 1.39 & 0.44 & $36,978.60$ & $36,522.32$ & 1.23 \\
\hline
\end{tabular}

Table 3. Cont.

\begin{tabular}{lcccccc}
\hline Specimens & $\boldsymbol{\lambda}$ & $\boldsymbol{\xi}_{\mathbf{i}}$ & $\boldsymbol{\xi}_{\mathbf{o}}$ & $\begin{array}{c}\boldsymbol{N}_{\mathbf{u}}^{\mathbf{c 4}} \\
\mathbf{k} \mathbf{N}\end{array}$ & $\begin{array}{c}\boldsymbol{N}_{\mathbf{u}}^{\mathbf{s}} \\
\mathbf{k N}\end{array}$ & $\begin{array}{c}\left|N_{\mathbf{u}}^{\mathbf{s}}-N_{\mathbf{u}}^{\mathbf{c}}\right| \\
N_{\mathbf{u}}^{\mathbf{s}}\end{array}$ \\
\hline CF19 & 7.8 & 1.39 & 0.44 & $36,465.80$ & $36,522.32$ & 0.16 \\
CF20 & 7.32 & 1.17 & 0.44 & $40,319.60$ & $40,560.31$ & 0.60 \\
CF21 & 7.32 & 1.10 & 0.44 & $42,130.80$ & $42,579.30$ & 1.06 \\
CF22 & 7.32 & 1.05 & 0.44 & $43,913.40$ & $44,598.29$ & 1.56 \\
CF23 & 7.32 & 0.96 & 0.44 & $33,471.20$ & $33,512.08$ & 0.12 \\
CF24 & 7.32 & 1.10 & 0.44 & $34,501.40$ & $34,507.63$ & 0.02 \\
CF25 & 7.32 & 1.68 & 0.44 & $38,662.80$ & $38,568.48$ & 0.24 \\
CF26 & 7.32 & 1.83 & 0.44 & $39,739.20$ & $39,603.36$ & 0.34 \\
CF27 & 7.32 & 1.38 & 0.44 & $35,951.90$ & $36,270.49$ & 0.89 \\
CF28 & 7.32 & 1.45 & 0.44 & $37,296.50$ & $36,772.82$ & 1.40 \\
CF29 & 7.32 & 1.94 & 0.44 & $41,503.70$ & $41,260.08$ & 0.59 \\
CF30 & 7.32 & 1.15 & 0.29 & $42,273.00$ & $42,249.72$ & 0.06 \\
CF31 & 7.32 & 1.08 & 0.25 & $44,960.50$ & $45,129.56$ & 0.38 \\
CF32 & 7.32 & 1.03 & 0.22 & $45,747.00$ & $48,014.78$ & 4.96 \\
CF33 & 7.43 & 0.98 & 0.17 & $30,327.20$ & $29,698.70$ & 2.07 \\
CF34 & 7.39 & 1.12 & 0.26 & $32,323.90$ & 31962.90 & 1.12 \\
CF35 & 7.25 & 1.65 & 0.61 & $41,039.90$ & $41,123.19$ & 0.20 \\
CF36 & 7.21 & 1.78 & 0.70 & $43,581.30$ & $43,439.20$ & 0.33 \\
CF37 & 6.19 & 1.18 & 0.37 & $47,236.70$ & $47,342.79$ & 0.22 \\
CF38 & 5.61 & 1.10 & 0.33 & $55,701.50$ & $55,318.11$ & 0.69 \\
CF39 & 5.36 & 1.07 & 0.32 & $60,229.70$ & $59,534.75$ & 1.15 \\
CF40 & 7.32 & 1.98 & 0.80 & $45,454.70$ & $45,883.30$ & 0.94 \\
CF41 & 6.34 & 1.39 & 0.44 & $36,815.70$ & $36,522.32$ & 0.80 \\
CF42 & 6.83 & 1.39 & 0.44 & $36,691.30$ & $36,522.32$ & 0.46 \\
\hline
\end{tabular}

According to the force mechanism of symmetrical CFDST composite stub columns, in addition to the axial load produced by the concrete and steel tube alone, the constraint effect of the steel tube on concrete should also be considered, and the constraint effect can enhance the bearing capacity of the concrete. The calculation expression of the axial compression bearing capacity $\left(N_{\mathrm{u}}^{\mathrm{c}}\right)$ for the CFDST full-scale specimens can be obtained by 
introducing the constraint effect coefficient $\left(\xi_{\mathrm{i}}, \xi_{\mathrm{o}}\right)$ of the inner and outer steel tubes, as is shown in Equation (10):

$$
N_{\mathrm{u}}^{\mathrm{c}}=A_{\mathrm{co}} f_{\mathrm{cko}}\left(1+A \xi_{\mathrm{o}}\right)+A_{\mathrm{ci}} f_{\mathrm{cki}}\left(1+b \xi_{\mathrm{i}}\right)+A_{\mathrm{si}} f_{\mathrm{yki}}+A_{\mathrm{so}} f_{\mathrm{sko}}
$$

where $a$ and $b$ are the adjustment coefficients, respectively.

The Levenberg-Marquardt optimization algorithm is used to regress the values of $a$ and $b$ in the 1stOpt software. The convergence criteria is achieved after 16 iterations, and the specific values of $a$ and $b$ are taken as 0.46 and 0.04 , respectively, as is shown in Equation (11).

$$
N_{\mathrm{u}}^{\mathrm{c} 4}=A_{\mathrm{co}} f_{\mathrm{cko}}\left(1+0.46 \xi_{\mathrm{o}}\right)+A_{\mathrm{ci}} f_{\mathrm{cki}}\left(1+0.04 \xi_{\mathrm{i}}\right)+A_{\mathrm{si}} f_{\mathrm{yki}}+A_{\mathrm{so}} f_{\text {sko }}
$$

The axial compression bearing capacity $\left(N_{\mathfrak{u}}^{c 4}\right)$ of 42 full-scale specimens, calculated using Equation (11), is shown in Figure 18. It can be seen from Figure 18 that the maximum error $\left(\right.$ Error $_{\text {Max }}$ ) between $N_{\mathrm{u}}^{\mathrm{s}}$ and $N_{\mathrm{u}}^{\mathrm{c4}}$ is $4.96 \%$, and both figures are in good agreement. It can be seen that Equation (11) has a high calculation precision, which can meet the requirements of practical engineering.

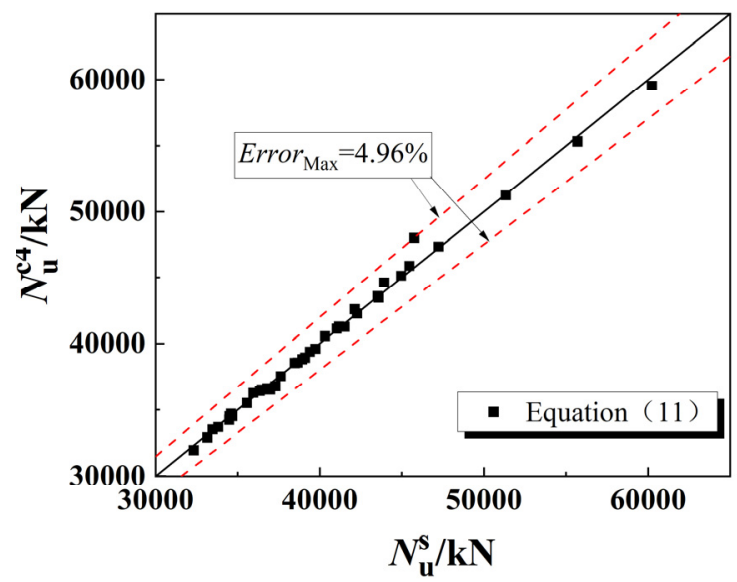

Figure 18. Comparisons between $N_{\mathfrak{u}}^{\mathrm{c} 4}$ and $N_{\mathfrak{u}}^{\mathrm{s}}$ of 42 specimens.

\section{Conclusions}

In the present paper, a novel assembled composite frame consisting of CFDST columns and $\mathrm{H}$-shaped honeycombed composite beams with RCFST flanges was proposed, and the study of the axial compression bearing behavior of symmetrical CFDST stub columns was conducted. The following conclusions can be drawn:

1. Using ABAQUS software, a systematic study on the bearing behavior of symmetrical CFDST stub columns was conducted. Based on the simplified bilinear constitutive model (CM) of steel tubes and the nonlinear CMs of core concrete and sandwich concrete, the numerical simulations of 26 test specimens were carried out. A comparison between the experimental curves and the FE analysis results showed that both were in good agreement. Therefore, the rationality of the CMs and FE modeling method was verified.

2. A further parameter study was carried out using the above modeling method. The results showed that the $N_{\mathrm{u}}^{\mathrm{s}}$ of the symmetrical CFDST stub columns increased significantly with the increase in $f_{\mathrm{cko}}, t_{\mathrm{o}}$, and $D_{\mathrm{o}}$. However, with the increase in $\lambda$, the $N_{\mathrm{u}}^{\mathrm{s}}$ of the symmetrical CFDST stub columns gradually decreased. All the specimens exhibited a superior load-holding capacity.

3. the deformation process of the symmetrical CFDST composite stub columns is mainly divided into 4 stages: firstly, bulging at the two ends, subsequently bulging from the two ends and gradually moving to the mid-section, continuously bulging from the 
mid-section and gradually moving to the whole, and finally failing when $\Delta_{\mathrm{c}}$ reaches above the limit deformation.

4. The calculation formula for the axial compression bearing capacity of stub columns based on the reduced-scale model would present a great error if it was applied to full-scale specimens. By referring to the formula for the axial compression capacity of the reducedscale model, the formula for calculating the axial compression bearing capacity of the symmetrical full-scale CFDST composite stub columns was obtained. The maximum error between the formula calculation and the finite element results was $4.96 \%$, which could meet the engineering requirements.

Author Contributions: Conceptualization, J.J.; software, W.B., Y.L. (Yunhao Li), R.W. and L.J.; validation, Y.L. (Yuchen Liu); writing—original draft, Y.L. (Yunhao Li), J.J. and L.J.; writing—review and editing, W.B., Y.L. (Yuchen Liu), L.Z. and L.H. All authors have read and agreed to the published version of the manuscript.

Funding: The authors are grateful for the financial support received from the Scientific Research Fund of the Institute of Engineering Mechanics, China Earthquake Administration, grant number 2020D07; the Natural Science Foundation of Heilongjiang Province, grant number LH2020E018; the Opening Fund for Key Laboratory of The Ministry of Education for Structural Disaster and Control of the Harbin Institute of Technology, grant number HITCE201908; The Social Science Foundation of Hebei Province, grant number HB20GL055; and the Northeast Petroleum University Guided Innovation Fund, grant number 2020YDL-02.

Institutional Review Board Statement: Not applicable.

Informed Consent Statement: Not applicable.

Data Availability Statement: The raw data supporting the conclusions of this article will be made available by the authors, without undue reservation.

Conflicts of Interest: The authors declare no conflict of interest. The funders had no role in the design of the study; in the collection, analyses, or interpretation of data; in the writing of the manuscript; or in the decision to publish the results.

\section{References}

1. Zheng, W.Z.; Wang, Y.; Liu, T.; Tan, J. Thoughts and understanding of remodeling of adding storeys around existing building. Ind. Constr. 2005, 4, 1-5.

2. Mirzaie, M.; Haji, S.R.M. Recognition the Architectural form of Tabriz's Hasht-Behesht Palace and its role in Formation process of Iranian Specimens and Neighboring Territories in the Course of 9th and 8th Centuries. Bagh-e Nazar 2017, 13, 81-92.

3. Zheng, W.Z.; Ji, J. Dynamic performance of angle-steel concrete columns under low cyclic loading-I: Experimental study. Earthq. Eng. Eng. Vib. 2008, 7, 67-75. [CrossRef]

4. Ji, J. Research on Seismic Performance and Design Method of Jacketing Steel Reinforced Concrete Frame Prestressed with Bonded Tendons. Ph.D. Thesis, Harbin Industry University, Harbin, China, 2008.

5. Ji, J.; Xu, Z.C. Nonlinear buckling analysis of H-type honeycombed composite column with rectangular concrete-filled steel tube flanges. Int. J. Steel Struct. 2018, 18, 1153-1166. [CrossRef]

6. Kim, S.K.; Lee, K.W. Dynamic responses of composite H-beams with different elastic couplings. J. Mech. Sci. Technol. 2011, 25, 2505-2517. [CrossRef]

7. Ji, J.; Zeng, W.; Wang, R.L.; Ren, H.G.; Zhang, L. Bearing Capacity of Hollow GFRP Pipe-Concrete-High Strength Steel Tube Composite Long Columns Under Eccentrical Compression Load. Front. Mater. 2021, 8, 1-15. [CrossRef]

8. Ji, J.; Yang, M.M.; Xu, Z.C.; Jiang, L.Q.; Song, H.Y. Experimental Study of H-Shaped Honeycombed Stub Columns with Rectangular Concrete-Filled Steel Tube Flanges Subjected to Axial Load. Adv. Civ. Eng. 2021, 2021, 6678623. [CrossRef]

9. Liu, Y.C.; Hang, Z.M. Analytical Solution for Lateral-Torsional Buckling of Concrete-Filled Tubular Flange Girders with Torsional Bracing. Adv. Civ. Eng. 2020, 2020, 4340381. [CrossRef]

10. Zhang, B.; Teng, J.G. Experimental behavior of hybrid frp-concrete-steel double-skin tubular columns under combined axial compression and cyclic lateral loading. Eng. Struct. 2015, 99, 214-231. [CrossRef]

11. Mander, J.B.; Priestley, M.J.N. Theoretical stress-strain model for confined concrete. J. Struct. Eng. 1988, 114, 1804-1826. [CrossRef]

12. Srinivasan, C.N.; Schneider, S.P. Axially loaded concrete-filled steel tubes. J. Struct. Eng. 1998, 124, 1125-1138. [CrossRef]

13. Portolés, J.M.; Romero, M.L. Experimental study of high strength concrete-filled circular tubular columns under eccentric loading. J. Constr. Steel Res. 2010, 64, 623-633. [CrossRef] 
14. Brown, N.K.; Kowalsky, M.J. Impact of D/t on seismic behavior of reinforced concrete filled steel tubes. J. Constr. Steel Res. 2015, 71, 111-123. [CrossRef]

15. Gholamreza, A.; Afaghi-Darabi, A. Effect of drywall and brick wall on fire behavior of concrete-filled steel tube column. Struct. Concrete. 2018, 19, 851-863.

16. Ekmekyapar, T.; Hasan, H.G. The influence of the inner steel tube on the compression behaviour of the concrete-filled double skin steel tube (CFDST) columns. Mar. Struct. 2019, 66, 197-212. [CrossRef]

17. Hasan, H.G.; Ekmekyapar, T. Mechanical Performance of Stiffened Concrete Filled Double Skin Steel Tubular Stub Columns under Axial Compression. KSCE J. Civ. Eng. 2019, 23, 2281-2292. [CrossRef]

18. Tao, Z.; Han, L.H. Behaviour of concrete-filled double skin (CHS inner and CHS outer) steel tubular stub columns and beamcolumns. J. Constr. Steel Res. 2004, 60, 1129-1158. [CrossRef]

19. Tao, Z.; Wang, X.Q. Stress-Strain Curves of Structural and Reinforcing Steels after Exposure to Elevated Temperatures. J. Mater. Civ. Eng. 2013, 25, 1306-1316. [CrossRef]

20. Lam, L.; Teng, J.G. Design-oriented stress-strain model for FRP-confined concrete. Constr. Build. Mater. 2003, 17, 471-489. [CrossRef]

21. Teng, J.G.; Yu, T. Hybrid FRP-concrete-steel tubular columns: Concept and behavior. Constr. Build. Mater. 2007, 21, 846-854. [CrossRef]

22. Pagoulatou, M.; Sheehan, T. Finite element analysis on the capacity of circular concrete-filled double-skin steel tubular (CFDST) stub columns. Eng. Struct. 2014, 72, 102-112. [CrossRef]

23. Nie, J.G.; Liao, Y.B. Bearing capacity calculations for concrete filled double skin tubes. J. Tsinghua Univ. 2008, 48, 312-315.

24. Fang, X.D.; Lin, S.J. Axial compressive test of columns with multi barrel tube-confined high performance concrete. J. Build. Struct. 2014, 35, 236-245.

25. Ekmekyapar, T.; AiEliwi, B.J.M. Concrete filled double circular steel tube (CFDCST) stub columns. Eng. Struct. 2017, 135, 68-80. [CrossRef]

26. Yu, D.Y. Research on Axial Compression and Seismic Performance of Solid-Web GFRP-Concrete-Steel Tube Composite Column. Master's Thesis, Northeast Petroleum University, Daqing, China, 2020.

27. Genikomsou, A.S.; Polak, M.A. Finite element analysis of punching shear of concrete slabs using damaged plasticity model in ABAQUS. Eng. Struct. 2015, 98, 38-48. [CrossRef]

28. Han, L.H.; Hou, C. Concrete-filled steel tubes subjected to axial compression: Life-cycle based performance. J. Constr. Steel Res. 2020, 170, 1-19. [CrossRef]

29. Dundu, M. Compressive strength of circular concrete filled steel tube columns. Thin Wall. Struct. 2012, 56, 62-70. [CrossRef]

30. Wang, Z.H. Experimental and Analytical Study of Double-Tube Concrete Column with an FRP External Tube and a High-Strength Steel Internal Tube. Ph.D. Thesis, Zhejiang University, Zhejiang, China, 2017; pp. 38-46.

31. Code for Design of Concrete Structures; GB 50010-2010; China Construction Industry Press: Beijing, China, 2010 ; pp. 19-26.

32. Gupta, P.K.; Khaudhair, Z.A. Modelling verification and investigation of behaviour of circular CFST columns. Struct. Concrete. 2015, 15, 340-349. [CrossRef]

33. Dai, X.; Lam, D. Numerical modelling of the axial compressive behavior of short concrete-filled elliptical steel columns. J. Constr Steel Res. 2010, 66, 931-942. [CrossRef]

34. Ji, J.; Yu, D.Y. Research on axial compression bearing capacity of different-strength concrete filled double steel tube short columns. Build. Struct. 2020, 50, 120-129. 